\title{
Residual layer ozone, mixing, and the nocturnal jet in California's San Joaquin Valley
}

\author{
Dani J. Caputi ${ }^{1}$, Ian Faloona ${ }^{1}$, Justin Trousdell ${ }^{1}$, Jeanelle Smoot ${ }^{1}$, Nicholas Falk ${ }^{1}$, and Stephen Conley ${ }^{2}$ \\ ${ }^{1}$ Department of Land, Air, and Water Resources, University of California Davis, Davis, 95616, USA \\ ${ }^{2}$ Scientific Aviation, Inc., Boulder, 80301, USA \\ Correspondence: Dani J. Caputi (djcaputi@ucdavis.edu)
}

Received: 17 August 2018 - Discussion started: 12 September 2018

Revised: 19 February 2019 - Accepted: 3 March 2019 - Published: 9 April 2019

\begin{abstract}
The San Joaquin Valley of California is known for excessive ozone air pollution owing to local production combined with terrain-induced flow patterns that channel air in from the highly populated San Francisco Bay area and stagnate it against the surrounding mountains. During the summer, ozone violations of the National Ambient Air Quality Standards (NAAQS) are notoriously common, with the San Joaquin Valley having an average of 115 violations of the current $70 \mathrm{ppb}$ standard each year between 2012 and 2016 . Because regional photochemical production peaks with actinic radiation, most studies focus on the daytime, and consequently the nocturnal chemistry and dynamics that contribute to these summertime high-ozone events are not as well elucidated. Here we investigate the hypothesis that on nights with a strong low-level jet (LLJ), ozone in the residual layer (RL) is more effectively mixed down into the nocturnal boundary layer (NBL) where it is subject to dry deposition to the surface, the rate of which is itself enhanced by the strength of the LLJ, resulting in lower ozone levels the following day. Conversely, nights with a weaker LLJ will sustain RLs that are more decoupled from the surface, retaining more ozone overnight, and thus lead to more fumigation of ozone the following mornings, giving rise to higher ozone concentrations the following afternoon. The relative importance of this effect, however, is strongly dependent on the net chemical overnight loss of $\mathrm{O}_{x}$ (here $\left[\mathrm{O}_{x}\right] \equiv\left[\mathrm{O}_{3}\right]+\left[\mathrm{NO}_{2}\right]$ ), which we show is highly uncertain, without knowing the ultimate chemical fate of the nitrate radical $\left(\mathrm{NO}_{3}\right)$. We analyze aircraft data from a study sponsored by the California Air Resources Board (CARB) aimed at quantifying the role of RL ozone in the high-ozone events in this area. By formulating nocturnal scalar budgets based on pairs of consecutive flights (the
\end{abstract}

first around midnight and the second just after sunrise the following day), we estimate the rate of vertical mixing between the RL and the NBL and thereby infer eddy diffusion coefficients in the top half of the NBL. The average depth of the NBL observed on the 12 pairs of flights for this study was $210( \pm 50) \mathrm{m}$. Of the average $-1.3 \mathrm{ppb} \mathrm{h}^{-1}$ loss of $\mathrm{O}_{x}$ in the NBL during the overnight hours from midnight to 06:00 PST, $-0.2 \mathrm{ppbh}^{-1}$ was found to be due to horizontal advection, $-1.2 \mathrm{ppb} \mathrm{h}^{-1}$ due to dry deposition, $-2.7 \mathrm{ppbh}^{-1}$ to chemical loss via nitrate production, and $+2.8 \mathrm{ppb} \mathrm{h}^{-1}$ from mixing into the NBL from the RL. Based on the observed gradients of $\mathrm{O}_{x}$ in the top half of the NBL, these mixing rates yield eddy diffusivity estimates ranging from 1.1 to $3.5 \mathrm{~m}^{2} \mathrm{~s}^{-1}$, which are found to inversely correlate with the following afternoon's ozone levels, providing support for our hypothesis. The diffusivity values are approximately an order of magnitude larger than the few others reported in the extant literature for the NBL, which further suggests that the vigorous nature of nocturnal mixing in this region, due to the LLJ, may have an important control on daytime ozone levels. Additionally, we propose that the LLJ is a branch of what is colloquially referred to as the Fresno eddy, which has been previously proposed to recirculate pollutants. However, vertical mixing from the LLJ may counteract this effect, which highlights the importance of studying the LLJ and Fresno eddy as a single interactive system. The synoptic conditions that are associated with strong LLJs are found to contain deeper troughs along the California coastline. The LLJs observed during this study had an average centerline height of $340 \mathrm{~m}$, average speed of $9.9 \mathrm{~m} \mathrm{~s}^{-1}\left(\sigma=3.1 \mathrm{~m} \mathrm{~s}^{-1}\right)$, and a typical peak timing around 23:00 PST. A total of 7 years of $915 \mathrm{MHz}$ radioacoustic sounding system and surface air quality network 
data show an inverse correlation between the jet strength and ozone the following day, further suggesting that air quality models need to forecast the strength of the LLJ in order to more accurately predict ozone violations.

\section{Introduction}

The main source of air for California's southern San Joaquin Valley (SSJV) is incoming maritime flow from the San Francisco Bay area, which gets accelerated toward the southern end of the valley as a consequence of the valley-mountain circulation (Rampanelli et al., 2004; Schmidli and Rottuno, 2010). The local sources of ozone precursors are scattered along this primary inflow path to the SSJV. The ozone buildup in the SSJV results from both the large amount of local upwind sources and the Tehachapi Mountains to the south, which block the flow and prevent advection out of the region (Dabdub et al., 1999; Pun et al., 2000). Because of this tendency for the air to stagnate, both daytime and nocturnal mesoscale dynamics are likely important in the phenomenology of ozone pollution in this area.

Under typical fair-weather conditions over the continents, thermals are generated near the surface beginning shortly after sunrise, buoyantly forcing a convectively mixed layer, which is known more generally as the daytime atmospheric boundary layer (ABL). As solar heating increases the Earth's surface temperature throughout the day, this layer reaches its maximum height by late afternoon, typically between 700 and $900 \mathrm{~m}$ in the SJV during summer months (Bianco et al., 2011). Around sunset, when the solar heating abates, the convective thermals shut off and no longer power turbulent mixing in the boundary layer. The result of the subsequent radiative cooling of the ground throughout the night forms a stable, nocturnal boundary layer (NBL), typically extending between 100 and $500 \mathrm{~m}$ (Stull, 1988) above the surface. The erstwhile convective layer from the daytime, after spinning down and no longer actively mixing, functions as a residual reservoir for pollutants and other trace gases from daytime emissions and photochemical production. This layer overlying the NBL is known as the residual layer (RL).

During both daytime and nighttime, mixing can occur between the boundary layer and the layer of air above. In the daytime over land in clear-sky conditions, this process of entrainment is driven by convective thermals that penetrate into the laminar free troposphere above and then sink back into the convective layer; it may be augmented by wind shear near the top of the boundary layer (Conzemius and Fedorovich, 2006). Entrainment has been shown to be a significant factor for near-surface air quality and more generally for scalar budgets, as the two interacting layers often have different trace gas concentrations (Lehning et al., 1998; Trousdell et al., 2016; Vilà-Guerau de Arellano et al., 2011). At night, another type of gas exchange can occur between the afore- mentioned NBL and the RL by shear-induced mixing. Extensive observations of the structure of the NBL indicate that a localized wind maximum near the top of the NBL, known as a low-level jet (LLJ), is often present (Banta et al., 2002; Garratt, 1985; Kraus et al., 1985). This LLJ is able to drive sheer production of turbulence, thereby promoting the mixing between these layers despite the stable stratification. In this study, we suggest that the LLJ in the SSJV is part of the northerly flow component of what is colloquially referred to as the Fresno eddy. As we attempt to show, the interaction between the LLJ and larger Fresno eddy is complex and raises an important question about whether the eddy simply recirculates ozone to exacerbate air pollution in the region, or whether the LLJ associated with the eddy induces enough vertical mixing to significantly deplete RL ozone and mitigate daytime ozone maxima. Our study uses aircraft observations in a large area of the SSJV (see Fig. 3), and thus these nocturnal mesoscale features are an important aspect of the scope of our work.

The Fresno eddy can drive both vertical mixing and regional horizontal advection. Monthly averaged wind speeds from June through August of the LLJ in the SSJV up to $12 \mathrm{~m} \mathrm{~s}^{-1}$ have been reported (Bianco et al., 2011), suggesting that shear-induced downward mixing of RL ozone in this region may be particularly strong. It has been previously shown that RL ozone can have a substantial correlation with ground-level ozone the following day (Aneja et al., 2000; Zhang and Rao, 1999). Using SODAR data from the Swiss plateau, Neu (1995) estimated that about $75 \%$ of the following day's early afternoon ozone was due to vertical mixing from the RL into the NBL. They also found a good correlation ( $r=0.74$ ) between weaker turbulence in the RL, inferred from the amount of time wind maxima at night were observed below $150 \mathrm{~m}$, and the aforementioned early afternoon ozone levels. Coupling of the RL and NBL via intermittent turbulence has also been shown to correlate with overnight ozone spikes at ground-level monitoring stations (Salmond and McKendry, 2005). Because of the complexity of intermittent nocturnal turbulence, the spatial and temporal distributions of these spikes are unknown, and thus the extent to which these ozone spikes help to deplete the RL ozone or contribute to the following day's ozone is unknown. A study from southern Taiwan also found that RL ozone plays an important role in the following day's ozone concentrations, with fumigation of this ozone into the developing daytime boundary layer accounting for $48 \%$ of the daily surface maximum (Lin, 2008).

Owing to the complex topography and stable stratification overnight, the dynamics of the NBL and RL in California are difficult to model. Bao et al. (2008) report that while the Weather Research and Forecasting (WRF) model is able to qualitatively capture the LLJ, systematic errors up to $2 \mathrm{~m} \mathrm{~s}^{-1}$ are observed, with root mean square errors of $4-5 \mathrm{~m} \mathrm{~s}^{-1}$. Above $2000 \mathrm{~m}$, a similar magnitude of errors in the model's ability to forecast wind is observed, and since the LLJ is in- 
fluenced by this upper-level synoptic forcing, there is a need for more systematic study of the background synoptic conditions associated with strong and weak LLJs.

At the core of our observational method, we recognize that most scalar budgets are driven by horizontal advection, vertical mixing, local emissions and uptake, and net chemical production (including chemical gains and/or losses). While many previous studies of daytime ozone budgets (Kleinman et al., 1994; Conley et al., 2011; Lehning et al., 1998; Lenschow et al., 1981; Trousdell et al., 2016) have shown that photochemical production is important, and a few nocturnal studies have highlighted significant losses of ozone in the dark (Brown et al., 2006; Stutz et al., 2010), we present here the first complete budget to include the mixing and chemistry overnight. The nocturnal ozone chemistry is primarily driven by its well-known reaction with $\mathrm{NO}_{2}$ to form the nitrate $\left(\mathrm{NO}_{3}\right)$ radical. The nitrate radical has many different loss pathways including combining with $\mathrm{NO}_{2}$ to equilibrate with $\mathrm{N}_{2} \mathrm{O}_{5}$ (which can undergo hydrolysis on surfaces), reacting with hydrocarbons, or reacting with NO to regenerate $\mathrm{O}_{3}$ and $\mathrm{NO}_{2}$ (Brown et al., 2006, 2007; Wood et al., 2005). As we will attempt to show, the chemical fate of the nitrate radical is highly uncertain and plays a critical role in the net overnight loss of ozone and consequently in our ability to predict the following day's ozone level. Additionally, dry deposition of the chemical species of interest cannot be ignored for scalar budgets (Conley et al., 2011; Faloona et al., 2009). While the aforementioned studies focused on daytime scalar budgets, to our knowledge, no attempts have been made at nocturnal scalar budgets using aircraft data. Our goal is to test whether more nocturnal mixing between the RL and NBL, induced by wind-shear turbulence beneath a strong LLJ, will deplete ozone in the RL, making less available to fumigate the following morning and seed further photochemical production. One advantage of the present study is that we use airborne data to sample a large area, which overcomes the limitations of studies using ground monitoring stations that may be influenced by the intermittent bursts of turbulence and confounds of uncertain horizontal advection. We will proceed with this in three ways: first, we introduce a method for analyzing the nocturnal scalar budgets of flight data, which is similar to that of the daytime scalar budgets, and attempt to estimate the eddy diffusivity of $\mathrm{O}_{x}$ in the NBL on each night of the field campaign (Sect. 3.1 and 3.2). Second, to determine whether our findings can be generalized to climatological timescales, we analyze synoptic conditions around the LLJ and look at a broader dataset of LLJ strength and the following afternoon's ozone concentrations using radioacoustic sounding system (RASS) and California Air Resources Board (CARB) ground network data (Sect. 3.3 and 3.4). Lastly, we look at other metrics of NBL turbulence in our campaign data such as turbulent kinetic energy (TKE), bulk Richardson number (BRN), and elevated mixed layers in order to further support our findings (Sect. 3.5 and 3.6).

\section{Nocturnal $O_{x}$ budgeting methodology}

\subsection{Airborne data collection}

Aircraft data were collected by a Mooney Bravo and Mooney Ovation, which are fixed-wing single-engine airplanes operated by Scientific Aviation, Inc. The wings are modified to sample air through inlets, which flow to the onboard analyzers. Temperature and relative humidity data were collected by a Visalia HMP60 humidity and temperature probe, ozone was measured with a dual-beam ozone absorption monitor (2B Technologies, model 205), and NO was measured by chemiluminescence (ECO PHYSICS, model CLD 88). $\mathrm{NO}_{x}$ was measured by utilizing a photolytic converter (model $42 \mathrm{i}$ BLC2-395 manufactured by Air Quality Design, Inc.). For flights performed in 2016, a pre-reaction chamber was also installed to monitor and subtract the changing background signal, reducing the detection threshold to $<50 \mathrm{ppt}$. Frequent calibrations were performed in the field, generally once per deployment, with zero and span checks daily. Calibrations for NO measurements were performed with a NIST-traceable standard by Scott-Marrin, Inc. Calibrations for $\mathrm{NO}_{x}$ measurements were performed by titrating the NO standard with an ozone generator (2B Technologies, model 206 Ozone Calibration Source.) During routine operation on the aircraft, the lamp of the photolytic converter was toggled on and off at $20 \mathrm{~s}$ intervals during the flights (corresponding to approximately $1.5 \mathrm{~km}$ horizontal and $50 \mathrm{~m}$ vertical displacements by the aircraft), requiring linear interpolation for continuous NO and $\mathrm{NO}_{2}$ data. The pre-reaction chamber was toggled on for a $40 \mathrm{~s}$ period every $10 \mathrm{~min}$ in order to measure the background signals of $\mathrm{NO}$ and $\mathrm{NO}_{x}$, and the background signals were subtracted from the measurement. The interpolated $\mathrm{NO}_{2}$ signal was noted to decay approximately exponentially after powering up, which sometimes affected the first 15-30 min of flight. The presumed artifact was successfully replicated in the laboratory with a constant $\mathrm{NO}_{2}$ concentration and was removed by exponential detrending.

Winds are measured using a dual-hemisphere global positioning system combined with direct airspeed measurements, as described in Conley et al. (2014). The winds are measured at $1 \mathrm{~Hz}$, and the power spectra are observed to fit the Kolmogorov scaling law within the inertial subrange (approximately $0.12-0.5 \mathrm{~Hz}$ in the daytime convective boundary layer corresponding to roughly $150-600 \mathrm{~m}$ spatial scales). At night, the $-5 / 3$ slope is observed from 0.02 to $0.5 \mathrm{~Hz}$ (Fig. 1), corresponding to length scales of 150 $3700 \mathrm{~m}$, the largest of which are likely contributions from buoyancy waves. This is evident by the calculated BruntVäisälä frequencies (Fig. 2), which have an average value of $0.023 \mathrm{~Hz}$ in the NBL. For simplicity's sake, we consider anything smaller than this buoyancy frequency to be "turbulence" and use $1 / N_{\mathrm{BV}} \sim 50 \mathrm{~s}$ as the sampling time to observe wind variances, though we recognize that this cutoff is somewhat arbitrary. The TKE is estimated by correcting the 


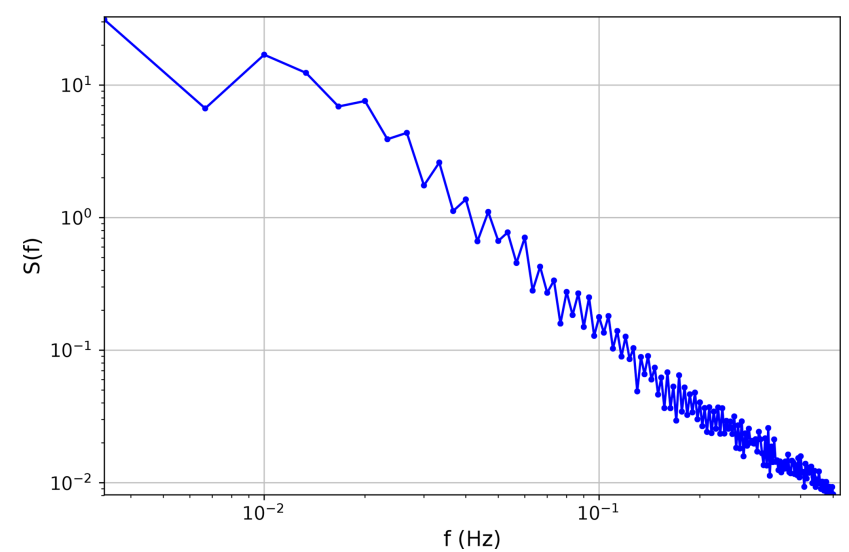

Figure 1. Power spectra for nighttime winds averaged over 309 5 min samples. The average airspeed was $76.6 \mathrm{~m} \mathrm{~s}^{-1}$.

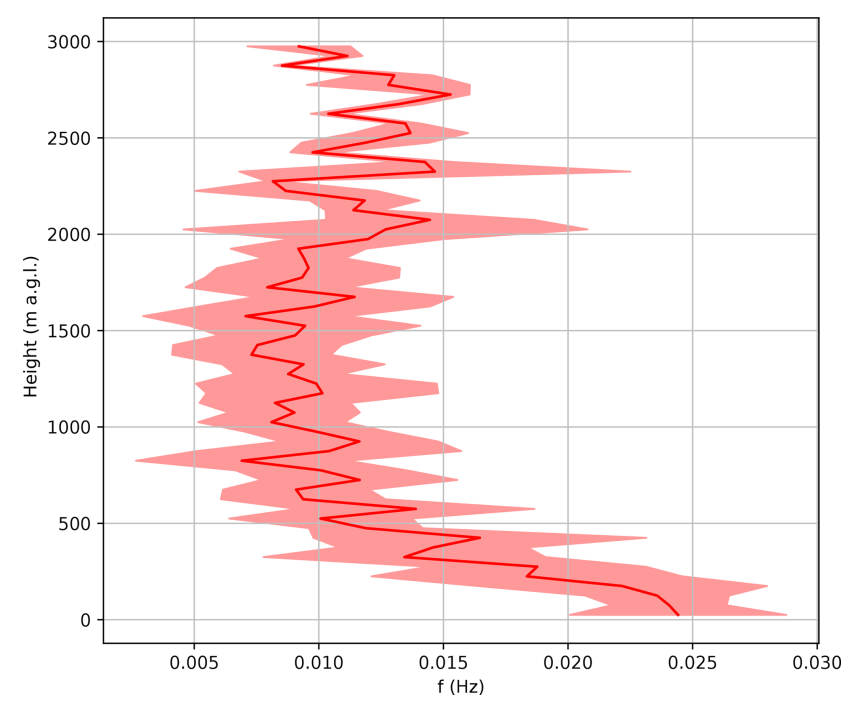

Figure 2. Mean and standard deviation profile of Brunt-Väisälä frequencies for all late-night flights. The mean value within the stable boundary layers is $0.023 \mathrm{~s}^{-1}$.

observed wind variance of a given detrended $50 \mathrm{~s}$ signal with the integrated nocturnal power spectra beyond the Nyquist frequency $(0.5 \mathrm{~Hz})$ using a $-5 / 3$ extrapolation, which indicates that approximately $11 \%$ of the total variance is not directly captured by the system. Only horizontal winds are measured, and thus similarity assumptions are required to estimate vertical wind variance $\left(\sigma_{\mathrm{w}}^{2}\right)$. While some similarity relationships have been reported for the NBL (Nieuwstadt, 1984), we were not able to measure the governing parameters. However, Banta et al. (2006) reported a meta-analysis of NBL studies with an average $\sigma_{\mathrm{w}}^{2} / \sigma_{\mathrm{u}}^{2}$ of 0.39 , where $\sigma_{\mathrm{u}}^{2}$ is the streamwise variance. We applied this correction to our TKE measurements to account for the missing vertical wind variance.

Data were collected on five separate deployments (1012 September 2015, 2-4 June 2016, 28-29 June 2016, 24-

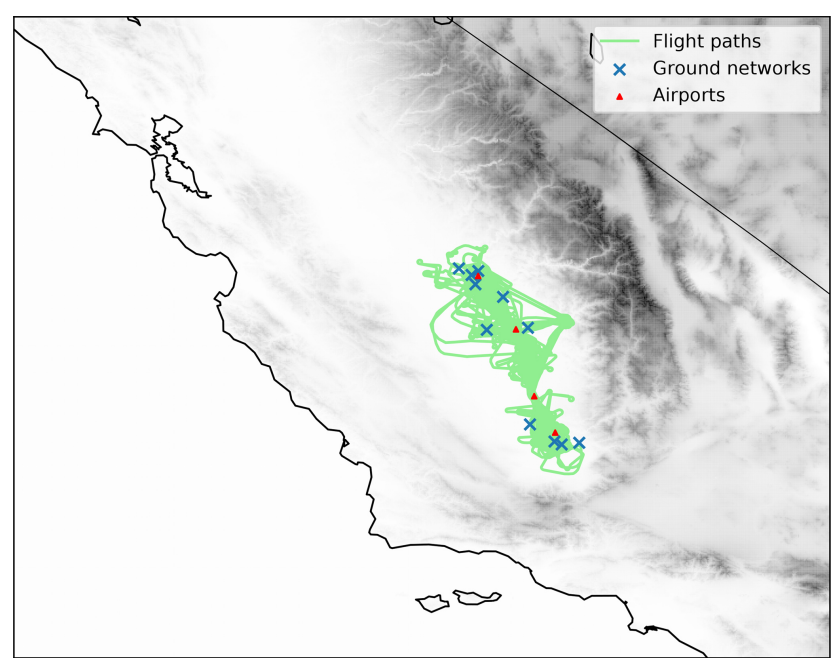

Figure 3. Flight paths of all aircraft deployments in this field campaign (green). Airports where low approaches were conducted (red triangles) and with ground ozone monitors (blue crosses) are shown. From north to south, the airports are Fresno Yosemite International Airport (FAT), Visalia Municipal Airport (VIS), Delano Municipal Airport (DLO), and Bakersfield Meadows Field Airport (BFL). From north to south, the CARB ground ozone network stations are Fresno Sierra Skypark no. 2, Clovis N Villa Avenue, Fresno Garland, Fresno Drummond Street, Parlier, Visalia N Church Street, Hanford S Irwin Street, Shafter Walker Street, Bakersfield 5558 California Avenue, Edison, and Bakersfield Municipal Airport.

26 July 2016, 12-18 August 2016). During a given deployment, four flights per day were conducted (07:00, 11:00, 15:00, and 22:00 PST). Each deployment consisted of stationing the airplane at Fresno Yosemite International Airport (FAT), with each flight comprising a transect to Bakersfield Meadows Field Airport (BFL) and back, spanning approximately $2 \mathrm{~h}$ and $15 \mathrm{~min}$ (Fig. 3). Profiles of the full boundary layer and above were taken at Fresno and Bakersfield. Along the Fresno-Bakersfield transect, altitude legs of 500,1000 , and $1500 \mathrm{~m}$ a.g.l. were conducted in a randomized order. Low passes were also flown over the Tulare (TLR), Delano (DLO), and Bakersfield airports, but in 2016 we replaced the low approaches at Tulare with Visalia (VIS) to coincide with the NOAA lidar deployment. All of these airports are within a few hundred meters of California Highway 99, or in the case of Fresno and Bakersfield within an urban center. If time permitted on any given flight, we typically completed an extra profile at Visalia or flew west toward Hanson to better sample the nocturnal LLJ.

The nocturnal scalar budget analyses presented here utilize all late-night $(\sim 21: 45-00: 00$ PST) flights for which a subsequent flight was conducted the following morning $(\sim$ 06:15-08:30 PST). The dates (before midnight PST) of the late-night flights for the 12 overnight periods are shown in Table 1. Additionally, late-night flights without a subsequent morning flight were flown on 12 September 2015 and 
26 July 2016, and morning flights without a preceding latenight flight were flown on 10 September 2015, 24 July 2016, 12 August 2016, and 14 August 2016. These additional flights are included in the analyses here that refer exclusively to either the late-night or morning flights, but they were not used for the scalar budgets.

\subsection{Scalar budget analysis}

Here we aim to test the importance of nocturnal mixing on the ozone budget in this region by applying a scalar budgeting technique to the aircraft data in order to estimate an eddy diffusivity between the NBL and the RL. To address this objective, we use a similar method that has been presented with daytime scalar budgets (Conley et al., 2011; Faloona et al., 2009; Trousdell et al., 2016) to further demonstrate the overall practicality of this methodology.

The nocturnal budget equation is formulated by the Reynolds-averaged conservation equation for a scalar - in this case $\mathrm{O}_{x}-$ in a turbulent medium. $\mathrm{O}_{x}$ is defined here as $\mathrm{NO}_{2}+\mathrm{O}_{3}$ in order to avoid the effects of the titration of $\mathrm{O}_{3}$ by NO. If not depleted by chemical oxidation to $\mathrm{NO}_{3}$ and further reaction products, $\mathrm{NO}_{2}$ will photolyze the following day to reproduce ozone in a photostationary state so it can act as an overnight reservoir of ozone. The chemical loss of $\mathrm{O}_{x}$ is then computed by the reaction between $\mathrm{O}_{3}$ and $\mathrm{NO}_{2}$ to form nitrate, and the ultimate fate of nitrate will affect the overall $\mathrm{O}_{x}$ loss. In the stable nighttime environment we will treat the mixing between the RL and NBL by using an eddy diffusivity. The NBL $\mathrm{O}_{x}$ budget can thus be represented as

$$
\begin{aligned}
\frac{\partial\left[\mathrm{O}_{x}\right]}{\partial t} & =-\alpha k_{\mathrm{O}_{3}+\mathrm{NO}_{2}}\left[\mathrm{O}_{3}\right]\left[\mathrm{NO}_{2}\right]-\bar{u} \frac{\overline{\Delta\left[\mathrm{O}_{x}\right]}}{\Delta x}-\bar{v} \frac{\overline{\Delta\left[\mathrm{O}_{x}\right]}}{\Delta y} \\
& +\frac{-\left[\mathrm{O}_{3}\right]_{\mathrm{SFC}} \cdot\left|v_{\mathrm{d}}\right|}{h}+\frac{K_{z} \frac{\Delta\left[\mathrm{O}_{x}\right]}{\Delta z}}{h},
\end{aligned}
$$

where the term on the left represents the change in concentration with respect to time. The leftmost term on the right side of Eq. (1) represents the net loss of $\mathrm{O}_{x}$ due to chemical reaction of the resultant $\mathrm{NO}_{3}$ and contains an unknown constant of proportionality, $\alpha$, which depends on the subsequent reaction pathway of $\mathrm{NO}_{3}$ and can range from 0 to 3 . For reasons discussed later, $\alpha$ is assumed to be $\sim 1.5$ for this analysis. The next two terms represent changes due to advection by the horizontal wind, followed by terms representing the dry deposition of ozone to the surface, and finally the vertical turbulent mixing term that uses the vertical gradient and the eddy diffusivity, $K_{z}$ - a number that encapsulates the strength of the overnight mixing. The storage (left-hand side) term, chemical loss, advection, surface ozone, and NBL height can be calculated using the aircraft data. Combining those measurements with an estimated $0.2 \mathrm{~cm} \mathrm{~s}^{-1}$ nighttime dry deposition velocity of ozone in the SSJV (an average from a study over cotton, grass, mixed deciduous forest, and vineyard field sites by Padro, 1996), we can indirectly estimate $K_{z}$. In the following sections, we detail the methods for estimating the terms in Eq. (1).

\subsubsection{NBL height}

Profiles of wind speed, potential temperature, $\mathrm{NO}_{2}$, and $\mathrm{O}_{3}$ from each night and morning flight were analyzed to make a best guess of the NBL height, $h$. Figure 4 shows the average scalar profiles from all 15 late-night flights to illustrate the typical gradients in the lower portion of the atmosphere. One method of determining $h$ is to observe the lowest elevation at which $\partial \theta / \partial z$ becomes close to adiabatic, as the layer below that physically represents air that is in thermodynamic communication with the radiatively cooled surface (Stull, 1988). Another method is to use the level of wind maximum, or LLJ height, when one is present. We found that both of these estimates typically yielded similar values of $h$. On nights when there was significant disagreement between the two different estimates, the vertical jump (or sharpest gradient) of $\mathrm{O}_{x}$ in the height region of the NBL-RL interface was considered, as this likely points to a region of maximum mixing. In such cases, we averaged the height at which the steepest gradient was observed with the estimates obtained from the other two methods. It should be noted that some subjectivity was involved for determining a final value of $h$ for each night because wind maxima and thermal gradients were not always clearly defined in the profiles. All of the aforementioned factors lead to an estimated uncertainty of $\pm 100 \mathrm{~m}$ for all of the NBL heights obtained. The average conditions from the latenight and morning flights are presented in Table 1.

For the domain of interest, all measured $\mathrm{NO}_{2}$ and $\mathrm{O}_{3}$ data were averaged for each $20 \mathrm{~m}$ altitude bin in order to generate mean vertical profiles of $\mathrm{O}_{x}$. Separate profiles were created for the late-night flight and the subsequent morning flight. The height of the NBL for each night $(h)$ was used as the upper altitude limit when averaging observations to obtain advection, chemical loss, and time rate of change (storage) terms for the budget equation, since the budget equation is meant to be applied to the NBL. The overnight average $\mathrm{O}_{x}$ profile was subtracted from the sunrise profile and divided by the time difference between the midpoints of each flight to compute the storage term.

\subsubsection{Nocturnal chemical loss of $\mathrm{O}_{x}$}

The chemical loss term in Eq. (1) is expected to be an important component of the NBL $\mathrm{O}_{x}$ budget. Both $\mathrm{NO}_{2}$ and $\mathrm{NO}_{3}$ are able to regenerate ozone in the presence of sunlight and participate in the same sequence of reactions; therefore, the species are normally grouped together into a family referred to as odd oxygen $\left(\mathrm{O}_{x}=\mathrm{O}_{3}+\mathrm{NO}_{2}+2 \mathrm{NO}_{3}+3 \mathrm{~N}_{2} \mathrm{O}_{5}\right)$ (Brown et al., 2006; Wood et al., 2005). However, since we did not measure $\mathrm{NO}_{3}$ and $\mathrm{N}_{2} \mathrm{O}_{5}$, in this study we estimate $\mathrm{O}_{x}$ as merely the sum of $\mathrm{O}_{3}+\mathrm{NO}_{2}$ because these are expected to exceed to concentrations of the other $\mathrm{O}_{x}$ species 

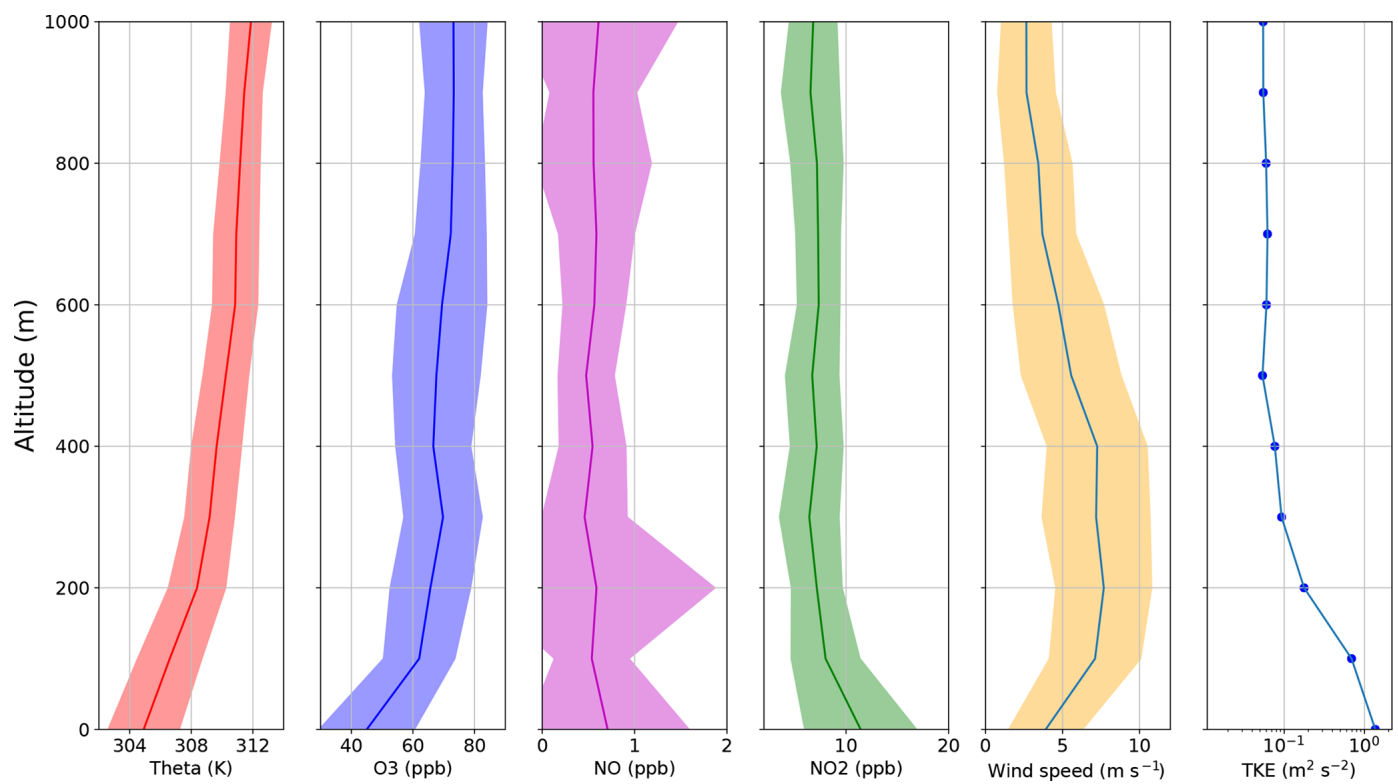

Figure 4. Mean and \pm 1 standard deviation (swathes) of potential temperature, ozone, $\mathrm{NO}, \mathrm{NO}_{2}$, wind speed, and turbulent kinetic energy (mean only) from all late-night flights.

Table 1. NBL heights, ozone, $\mathrm{NO}_{2}$, Brunt-Väisälä (BV) frequencies, bulk Richardson number (BRN), turbulent kinetic energy (TKE), and LLJ maximum wind speeds observed during the late-night and morning flight pairs. Maximum daily $8 \mathrm{~h}$ average ozone (MDA8) values are from the following day and are an average of the 11 ground networks in our flight region.

\begin{tabular}{|c|c|c|c|c|c|c|c|c|c|}
\hline Flight date & $\begin{array}{r}\text { NBL height } \\
h(\mathrm{~m})\end{array}$ & $\begin{array}{r}\mathrm{NBL} \mathrm{O}_{3} \\
(\mathrm{ppbv})\end{array}$ & $\begin{array}{r}\mathrm{NBL} \mathrm{NO}_{2} \\
(\mathrm{ppbv})\end{array}$ & $\begin{array}{r}\text { MDA8 } \\
(\mathrm{ppbv})\end{array}$ & $\begin{array}{r}\text { BV frequency } \\
\qquad N\left(\mathrm{~s}^{-1}\right)\end{array}$ & BRN & $\begin{array}{r}\text { TKE } \\
\left(\mathrm{m}^{2} \mathrm{~s}^{-2}\right)\end{array}$ & $\begin{array}{r}\text { LLJ max } \\
U_{x}\left(\mathrm{~m} \mathrm{~s}^{-1}\right)\end{array}$ & $\sigma_{u} / U_{x}$ \\
\hline 9 Sep 2015 & 250 & 45.4 & 16.5 & 82.7 & 0.025 & 0.68 & 0.35 & 8.1 & 0.09 \\
\hline 12 Sep 2015 & 130 & 31.2 & 18.5 & 67.2 & 0.018 & 0.89 & 0.70 & 4.0 & 0.22 \\
\hline 3 Jun 2016 & 260 & 52.7 & 6.0 & 87.8 & 0.021 & 0.23 & 0.35 & 12.0 & 0.05 \\
\hline 4 Jun 2016 & 220 & 59.0 & 6.1 & 92.3 & 0.026 & 0.80 & 0.50 & 5.9 & 0.12 \\
\hline 29 Jun 2016 & 150 & 43.0 & 9.9 & 91.9 & 0.022 & 0.28 & 0.41 & 10.0 & 0.08 \\
\hline 25 Jul 2016 & 190 & 44.2 & 12.0 & 85.5 & 0.022 & 0.71 & 0.43 & 6.4 & 0.10 \\
\hline 26 Jul 2016 & 320 & 51.6 & 8.7 & 94.8 & 0.023 & 0.99 & 0.56 & 8.0 & 0.08 \\
\hline 13 Aug 2016 & 150 & 49.8 & 13.9 & 92.1 & 0.017 & 0.41 & 0.61 & 9.1 & 0.08 \\
\hline 15 Aug 2016 & 250 & 42.5 & 11.6 & 74.3 & 0.023 & 0.37 & 1.02 & 10.3 & 0.08 \\
\hline 16 Aug 2016 & 210 & 44.8 & 14.1 & 86.8 & 0.025 & 0.52 & 0.71 & 9.4 & 0.10 \\
\hline 17 Aug 2016 & 170 & 48.3 & 15.9 & 91.5 & 0.024 & 1.35 & 0.74 & 6.2 & 0.12 \\
\hline 18 Aug 2016 & 190 & 48.8 & 12.6 & 92.2 & 0.025 & 1.00 & 0.71 & 5.6 & 0.17 \\
\hline Average & 208 & 46.8 & 12.1 & 86.6 & 0.023 & 0.69 & 0.59 & 7.9 & 0.11 \\
\hline SD & 53 & 6.5 & 3.8 & 7.9 & 0.003 & 0.32 & 0.19 & 2.2 & 0.04 \\
\hline
\end{tabular}

by 1-2 orders of magnitude (Brown et al., 2003; Smith et al., 1995). Considering $\mathrm{O}_{x}$ is useful for our study because the family is conserved in the rapid oxidation of $\mathrm{NO}$ by $\mathrm{O}_{3}$ (Reaction $\mathrm{R} 1$ below) yielding $\mathrm{NO}_{2}$, which may be quickly photolyzed to regenerate $\mathrm{O}_{3}$ once the sun rises as part of the standard daytime photostationary state.

Aside from dry deposition to the Earth's surface, $\mathrm{NO}_{x}$ chemistry is the main loss of ozone at night, counteracting its role in production during the daytime (Brown et al., 2006, 2007). The chemical loss of ozone at night begins with the production of the nitrate radical (Reaction R2).

$\mathrm{NO}+\mathrm{O}_{3} \rightarrow \mathrm{NO}_{2}+\mathrm{O}_{2}$

$\mathrm{NO}_{2}+\mathrm{O}_{3} \rightarrow \mathrm{NO}_{3}+\mathrm{O}_{2}$

$\mathrm{NO}_{3}$ photolyzes rapidly once the sun rises, so the ultimate net loss of ozone depends on the loss of nitrate in the dark. The loss occurs mainly via three general channels. In one channel, dinitrogen pentoxide is formed (Reaction R3), which has a backwards reaction and can be a source of $\mathrm{NO}_{2}$ if not de- 
posited onto moist surfaces or aerosols to form nitric acid via hydrolysis (Reaction R4).

$\mathrm{NO}_{3}+\mathrm{NO}_{2}+\mathrm{M} \leftrightarrow \mathrm{N}_{2} \mathrm{O}_{5}+\mathrm{M}$

$\mathrm{N}_{2} \mathrm{O}_{5}+\mathrm{H}_{2} \mathrm{O} \rightarrow 2 \mathrm{HNO}_{3}$

$\mathrm{NO}+2 \mathrm{O}_{3}+\mathrm{NO}_{2} \rightarrow 2 \mathrm{NO}_{z}$

$\mathrm{NO}_{z}=\mathrm{NO}_{y}-\mathrm{NO}_{x}$ represents the family of products of $\mathrm{NO}_{x}$ oxidation. In another channel, nitrate is lost by reaction with a wide array of organic compounds. This process can typically be represented by Reaction (R5), but in some cases, organic compounds can become rearranged to produce an $\mathrm{NO}_{2}$ molecule (Reactoin R5a) (Brown et al., 2006).

$\mathrm{NO}_{3}+$ (VOC, etc.) $\rightarrow$ organic nitrates

$\mathrm{NO}_{3}+($ VOC, etc. $) \rightarrow$ organic nitrates $+\mathrm{NO}_{2}$

$\mathrm{NO}+2 \mathrm{O}_{3} \rightarrow \mathrm{NO}_{z}$

(Net (R1, R2, R5))

$\mathrm{NO}+2 \mathrm{O}_{3} \rightarrow \mathrm{NO}_{z}+\mathrm{NO}_{2}$

(Net (R1, R2, R5a))

However, in urban environments with nocturnal sources of $\mathrm{NO}$, nitrate is reduced back to $\mathrm{NO}_{2}$ by very rapid reaction.

$\mathrm{NO}+\mathrm{NO}_{3} \rightarrow 2 \mathrm{NO}_{2}$

$2 \mathrm{NO}+2 \mathrm{O}_{3} \rightarrow 2 \mathrm{NO}_{2}$

(Net (R1, R2, R6))

If the hydrolysis of $\mathrm{N}_{2} \mathrm{O}_{5}$ (Reaction $\mathrm{R} 4$ ) is the dominant $\mathrm{NO}_{3}$ sink, then the net reaction leads to a loss of three $\mathrm{O}_{x}$ molecules per nitrate produced (Reaction R2). However, if the dominant loss is reaction with VOCs then the net reaction leads to between one (Reaction R5a) and two (Reaction R5) $\mathrm{O}_{x}$ molecules lost per R2. And if there is sufficient NO, Reaction (R6) will dominate the nitrate loss, leading to no net $\mathrm{O}_{x}$ loss per Reaction (R2). Thus, determining the dominant loss of nitrate is crucial for any analysis of the diurnal budget of ozone.

Reaction (R6) has often been ignored at night under the presumption that local sources of NO are sparse and Reaction (R1) will outcompete Reaction (R6) (Brown et al., 2007; Stutz et al., 2010). However, at observed values of $30 \mathrm{ppb}$ of $\mathrm{O}_{3}$ and an estimated 20 ppt of $\mathrm{NO}_{3}$ (Smith et al., 1995), the lifetime of $\mathrm{NO}(\sim 80 \mathrm{~s})$ with respect to Reaction (R1) would be nearly equivalent to that of Reaction (R6). Our measurements indicate ground-level NO of about $0.6 \mathrm{ppb}$ at midnight $(\sigma=1 \mathrm{ppb})$, corroborated by the CARB surface air quality network, increasing in the early morning hours to $2-$ $4 \mathrm{ppb}$. However, both the ground network and aircraft observations may be biased high to the regional average because of their proximity to California Highway 99 and other urban centers (Fig. 3). Nevertheless, the rate of Reaction (R6) is $2.6 \times 10^{-11} \mathrm{~cm}^{3} \mathrm{~s}^{-1} \mathrm{molec}^{-1}$ (Sander et al., 2006), extremely rapid relative to the others, such that even $60 \mathrm{ppt}$ of NO (an order of magnitude lower than what our measurements indicate) would result in an $\mathrm{NO}_{3}$ lifetime of only $25 \mathrm{~s}$. Hence, we conclude that Reaction (R6) should not be ignored in general as it may ultimately reduce the chemical loss rate of $\mathrm{O}_{x}$ overnight.
There is then a further question as to whether any VOCs would be able to compete with this channel of $\mathrm{NO}_{3}$ consumption. An investigation into the most rapid VOC reactions with $\mathrm{NO}_{3}$ per Atkinson et al. (2006) and Gentner et al. (2014a) is presented in Table 2. In this analysis, concentrations of VOCs are estimated from available reports in the SJV, which given its roughly 5 million acres of irrigated land ( $\mathrm{Li}$ et al., 2016) may vary widely from one location to another due to the presence of diverse crop canopies. The estimated lifetime of $\mathrm{NO}_{3}$ due to the VOC reactions in Table 2 is $12.2 \mathrm{~s}$, about 5 times the lifetime of $\mathrm{NO}_{3}$ with respect to the presence of $0.6 \mathrm{ppb}$ of $\mathrm{NO}(2.5 \mathrm{~s})$. We note that although there are few direct observations of $\mathrm{NO}_{3}$ in the SSJV, the CalNex campaign conducted one flight that measured concentrations of about 10-40 ppt shortly after sunset on 24 May 2010 (https://esrl.noaa.gov/csd/groups/csd7/ measurements/2010calnex/P3/DataDownload/index.php, last access: 30 April 2018). Smith et al. (1995) present DOAS measurements from 15 nights in July and August 1990 (their Fig. 6a) from a site $32 \mathrm{~km}$ southeast of Bakersfield suggesting that $\mathrm{NO}_{3}$ concentrations in the SSJV peak around $30 \mathrm{pptv}$ within an hour or two after sunset and plateau in the middle of the night around $10 \mathrm{ppt}$, then decline to zero by sunrise. The variability of $\mathrm{NO}_{3}$ reported in that study is high, with nocturnal values ranging from near zero to over $50 \mathrm{ppt}$. Under a simplified, steady-state model, the expected lifetime of $\mathrm{NO}_{3}$ can be estimated using the second-order reaction rate for Reaction (R2) for the formation of the nitrate radical and combining all of the loss channels into a single lifetime $\left(\tau_{\mathrm{NO}_{3}}\right)$ :

$\tau_{\mathrm{NO}_{3}}=\frac{\left[\mathrm{NO}_{3}\right]}{k_{2}\left[\mathrm{NO}_{2}\right]\left[\mathrm{O}_{3}\right]}$.

Using the average NBL ozone and $\mathrm{NO}_{2}$ from Table 1 , an $\mathrm{NO}_{3}$ concentration of $10 \mathrm{ppt}$ would imply its lifetime to be about $25 \mathrm{~s}$, which is about twice as large as our estimate from Table 2. Based on these direct measurements of $\mathrm{NO}_{3}$, our lifetime calculations likely represent a lower bound and further illustrate the uncertainty given the sensitivity to the unconstrained VOCs and our NO measurements, which have an envelope of error that spans a large range of possible nitrate loss lifetimes.

With longer lifetimes of nitrate loss with respect to the VOC and NO reactions, we are faced with the possibility that the hydrolysis of $\mathrm{N}_{2} \mathrm{O}_{5}$ is also an important loss channel, increasing the amount of $\mathrm{O}_{x}$ molecules lost per nitrate molecule formation in Reaction (R2). Smith et al. (1995) report that the lifetime of $\mathrm{NO}_{3}$ was found to be highly dependent on relative humidity, with lifetimes ranging from seconds to $10 \mathrm{~min}$ when the relative humidity is above $45 \%$ (presumably due to $\mathrm{N}_{2} \mathrm{O}_{5}$ hydrolysis) but between 10 and 60 min when below the $45 \%$ threshold. Figure 5 shows the diurnal cycle of temperature and relative humidity observed at the airports in our flight region during the days of our campaign compared with the 2015-2016 1 June-30 September 
Table 2. Estimations of VOC reactions with nitrate in the summertime nocturnal boundary layer for the SSJV. Reaction rates from Atkinson and Arey (1998), Table 2, and Atkinson et al. (2006).

\begin{tabular}{|c|c|c|c|c|}
\hline VOC & $\mathrm{cm}^{3} \mathrm{mlc}^{-1} \mathrm{~s}^{-1}$ & $\begin{array}{r}\text { Best guess } \\
\text { ppt }\end{array}$ & $\begin{array}{r}\tau_{\mathrm{NO}_{3}} \\
\mathrm{~s}\end{array}$ & Source \\
\hline$o$-cresol & $3.33\left(10^{-11}\right)$ & 10 & 120 & Estimate $^{1}$ \\
\hline linalool & $2.22\left(10^{-11}\right)$ & 50 & 36 & Arey et al. $(1991)^{3}$ \\
\hline 3-methylfuran & $1.90\left(10^{-11}\right)$ & 9 & 235 & Steiner et al. (2008) \\
\hline$b$-caryophyllene & $1.67\left(10^{-11}\right)$ & 13 & 190 & Gentner et al. (2014b) \\
\hline 6-methyl-5-hepten-2-one & $1.67\left(10^{-11}\right)$ & 10 & 241 & Estimate $^{2}$ \\
\hline limonene & $1.33\left(10^{-11}\right)$ & 26 & 117 & CalNex \\
\hline myrcene & $1.11\left(10^{-11}\right)$ & 29 & 124 & Gentner et al. (2014b) \\
\hline sabinene & $9.52\left(10^{-12}\right)$ & 3 & 1284 & CalNex \\
\hline$b$-phellandrene & $8.33\left(10^{-12}\right)$ & 10 & 482 & Estimate $^{2}$ \\
\hline Phenol & $7.41\left(10^{-12}\right)$ & 10 & 542 & Estimate $^{2}$ \\
\hline$a$-pinene & $6.06\left(10^{-12}\right)$ & 47 & 142 & CalNex \\
\hline$b$-pinene & $2.67\left(10^{-12}\right)$ & 3 & 4654 & CalNex \\
\hline trans-2-butene & $7.94\left(10^{-13}\right)$ & 130 & 389 & Steiner et al. (2008) \\
\hline isoprene & $6.94\left(10^{-13}\right)$ & 68 & 853 & CalNex \\
\hline camphene & $6.54\left(10^{-13}\right)$ & 7 & 8502 & CalNex \\
\hline NET & & & 12.2 & \\
\hline
\end{tabular}

\footnotetext{
${ }^{1}$ Drew Gentner of Yale University, personal communication. ${ }^{2}$ No measurements reported in the SSJV; an order of magnitude estimate is made based on typical aerosol concentrations. ${ }^{3}$ Arey et al. (1991) reported $70 \mathrm{ppt}$ in an orange grove. We estimate $50 \mathrm{ppt}$ as an SJV average.
}

averages. The $>45 \%$ relative humilities observed at FAT and VIS imply that the hydrolysis of $\mathrm{N}_{2} \mathrm{O}_{5}$ is an important sink for $\mathrm{NO}_{3}$.

Given the importance of nitrate loss to VOCs and NO, but some importance of the $\mathrm{N}_{2} \mathrm{O}_{5}$ hydrolysis, we use a best estimate that each effective collision of $\mathrm{NO}_{2}$ and $\mathrm{O}_{3}$ will lead to the net loss of approximately $1.5( \pm 0.5)$ molecules of $\mathrm{O}_{x}$ from the net effects of the entire series of reactions outlined above. This is a "center of the envelope" estimate for the possible range of 0-3. Although our measurements are unable to constrain this coefficient, the ultimate fate of the nitrate radical can be seen to have a critical role in quantifying the net loss of $\mathrm{O}_{x}$ overnight, and without a greater understanding of the nitrate budget, predicting this loss rate is uncertain.

Consequently, we calculate the net Reaction (R1-R6) for the nocturnal chemical loss rate of $\mathrm{O}_{x}$ as a constant multiple of Reaction (R2). The second-order rate equation for the net chemical loss of $\mathrm{O}_{x}$ is calculated by

$$
\left.\frac{\mathrm{dO}_{x}}{\mathrm{~d} t}\right|_{\text {chemical loss }}=-\alpha k_{\mathrm{O}_{3}+\mathrm{NO}_{2}}\left[\mathrm{O}_{3}\right]\left[\mathrm{NO}_{2}\right],
$$

where $\alpha$ can range from 0 to 3 and, per the discussion above, is estimated to be $1.5 \pm 0.5$ (uncertainty discussed in Sect. 3.2). To estimate a value for the second-order rate constant $\left(k_{\mathrm{O}_{3}+\mathrm{NO}_{2}}\right)$, we start with the temperature-dependent function for this reaction (Sander et al., 2006):

$k_{\mathrm{O}_{3}+\mathrm{NO}_{2}}=1.2\left(10^{-13}\right) \cdot e^{\frac{-2450}{T}}$, where $T$ is the temperature in Kelvin. For the domain being analyzed, an instantaneous value of $k_{\mathrm{O}_{3}+\mathrm{NO}_{2}}$ is determined at each data point. These values of $k_{\mathrm{O}_{3}+\mathrm{NO}_{2}}$ are then averaged to obtain a constant value for the given night. It should be noted that small errors in the value of $k$ that are within the order of our temperature fluctuations were found not to have a measurable impact on the chemical loss term. To estimate the chemical loss of $\mathrm{O}_{x}$, the initial $20 \mathrm{~m}$ altitude bins for $\mathrm{NO}_{2}$ and $\mathrm{O}_{3}$ are taken from the late-night and morning profiles. In each bin, the concentrations are linearly interpolated between the late-night and morning values so that there is an estimation of the current average concentration within that bin at every time during the night.

\subsubsection{Horizontal advection by mean wind}

The advection term in Eq. (1) is calculated by first collecting all $1 \mathrm{~s} \mathrm{O}_{x}$ data points for the late-night and morning flights separately. For each flight, a multiple linear regression is fit through the $1 \mathrm{~s} \mathrm{O}_{x}$ data for latitude $(y)$, longitude $(x)$, and altitude $(z)$, allowing for estimations of the horizontal gradients of $\mathrm{O}_{x}\left(\partial\left[\mathrm{O}_{x}\right] / \partial x\right.$ and $\left.\partial\left[\mathrm{O}_{x}\right] / \partial y\right)$ in the horizontal advection term. The $r^{2}$ values of the regressions ranged from 0.25 to 0.69 , and the number of data points that they contained ranged from 2813 to 5323. Typical values of the horizontal $\mathrm{O}_{x}$ gradients were of order $0.1 \pm 0.02 \mathrm{ppb} \mathrm{km}^{-1}$. To compute the total advection term within the NBL on a given flight, 

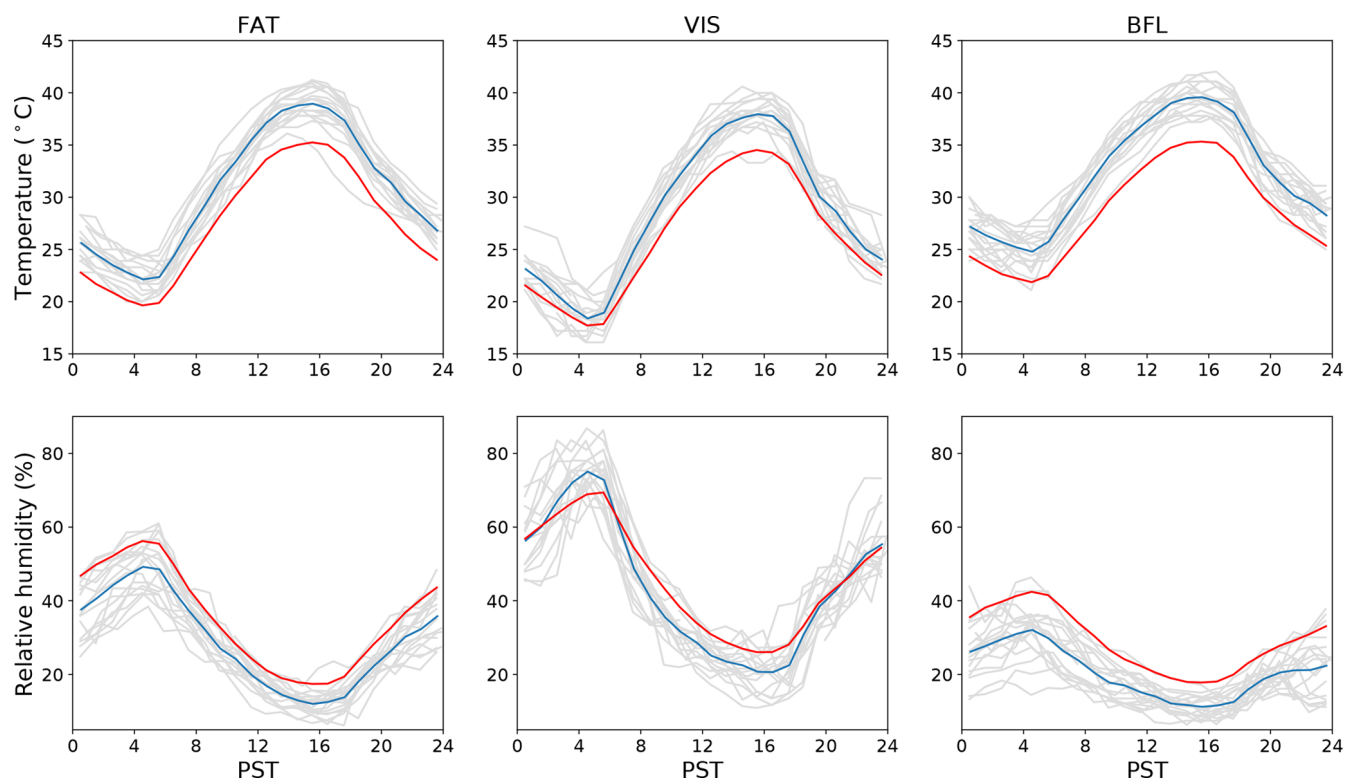

Figure 5. Diurnal plots of temperature and relative humidity during flight days of the Residual Layer Ozone campaign (individual days: grey lines, campaign average: blue lines) compared to 1 June-30 September 2015 and 2016 averages (red lines) at the Fresno (FAT), Visalia (VIS), and Bakersfield (BFL) airports as part of the Automated Weather Observing System (AWOS) network. Hours are in Pacific Standard Time (PST).

these gradients are combined with the mean wind speeds.

Advection $\quad \mathrm{O}_{x}=-\left[\left(\frac{\partial\left[\mathrm{O}_{x}\right]}{\partial x} \cdot \bar{u}\right)+\left(\frac{\partial\left[\mathrm{O}_{x}\right]}{\partial y} \cdot \bar{v}\right)\right]$

Per convention, $u$ is the mean $x$ component (zonal) wind and $v$ is the mean $y$ component (meridional) wind. The same procedure is repeated for the morning flights, and the advection terms from the late-night and morning flights are averaged together.

\subsubsection{Dry deposition of $\mathrm{O}_{x}$}

Dry deposition of ozone is presumed to be an important sink of $\mathrm{O}_{x}$ at the surface, the flux of which can be parameterized as the product of the surface ozone values (measured directly from the aircraft) and the deposition velocity for ozone. There are reports of ozone deposition in the area of our field campaign from a 1994 study using the eddy covariance technique (Padro, 1996). The findings of that study suggest nocturnal ozone deposition velocities are several times smaller than their daytime counterparts, but we infer that the overall process is still important for the budget in the NBL because of the smaller mixed-layer depth (Eq. 1). Based on an abundance of observations of nocturnal ozone dry deposition velocities reported in the literature over a broad variety of grassland and agricultural surfaces similar to those found in the SSJV (Pederson et al., 1995; Pio et al., 2000; Mészáros et al., 2009; Neirynck et al., 2012; Lin et al., 2010), all ranging about $0.1-0.3 \mathrm{~cm} \mathrm{~s}^{-1}$, we estimate a dry deposition velocity of $0.2 \mathrm{~cm} \mathrm{~s}^{-1}\left( \pm 0.1 \mathrm{~cm} \mathrm{~s}^{-1}\right)$ for our purposes. We ignore
$\mathrm{NO}_{2}$ deposition on the basis that crop canopies can either be a small source or sink of $\mathrm{NO}_{2}$ at the surface (Walton et al., 1997). The amount of $\mathrm{O}_{x}$ lost overnight due to deposition would be within our stated uncertainty $\left( \pm 0.86 \mathrm{ppb} \mathrm{h}^{-1}\right)$ as long as $\left|v_{\mathrm{d} \mathrm{N}_{2}}\right|<\sim 2.5 \mathrm{~cm} \mathrm{~s}^{-1}$, an assumption supported by the literature (Pilegaard et al., 1998; Walton et al., 1997).

\subsubsection{Vertical turbulent mixing between the NBL and the RL}

Finally, a vertical flux divergence for $\mathrm{O}_{x}$ must be estimated for Eq. (1), which is represented by the last two terms. For the top part of the NBL, the flux of $\mathrm{O}_{x}$ can be interpreted as an eddy diffusivity $\left(K_{z}\right)$ multiplied by the vertical gradient of $\mathrm{O}_{x}$ between the NBL and RL. For each flight, a linear regression through the $1 \mathrm{~s} \mathrm{O}_{x}$ data within the NBL-RL interface is used to determine $\partial\left[\mathrm{O}_{x}\right] / \partial z$ (for the last term in Eq. 1) in the upper portion of the NBL that appeared to contain the strongest $\mathrm{O}_{x}$ gradient. The average $r^{2}$ value of the 24 regressions was 0.11 , and the number of data points that they contained ranged from 116 to 2166 . Typical values of the vertical $\mathrm{O}_{x}$ gradients were $\sim 0.07 \pm 0.04 \mathrm{ppb} \mathrm{m}^{-1}$. The layers used for the regression fit were 100-200 m thick and did not extend below $70 \mathrm{~m}$ a.g.l. to avoid capturing the region where the $\mathrm{O}_{x}$ sink due to surface deposition and/or reaction with freshly emitted NO likely accounts for the vertical gradient in $\mathrm{O}_{x}$ (Fig. 6). The eddy diffusivity can now be solved for with all of the other terms estimated.

The contribution of vertical mixing to the budget can be visualized as an inferred difference between $\mathrm{O}_{x}$ profiles that 
are observed and $\mathrm{O}_{x}$ profiles that are predicted from other terms in Eq. (1). Figure 6 shows an example of the observed profiles of $\mathrm{O}_{x}$ on the late-night and morning flights for the series performed on 4 June 2016. The height of the NBL is shown (green), and the lower bound of the layer used in the vertical gradient fit is shown (yellow). The dashed profiles show the expected profile that would have been observed on the morning flight if only advection (blue), chemical loss (green), or both advection and chemical loss (red) processes were occurring. The observed morning $\mathrm{O}_{x}$ (magenta) is inferred to exceed the predicted morning $\mathrm{O}_{x}$ (red) due to the vertical mixing term in the scalar budget equation.

\section{Results and discussion}

\section{1 $O_{x}$ scalar budget results}

Results of the scalar budget analysis for all 12 paired latenight and morning flights are presented in Table 3. An error propagation analysis (discussed in Sect. 3.2) is presented for each term in the budget, and for the $K_{z}$ values.

Of note is the fact that, on average, the chemical loss is expected to be a little more than twice as large as the physical loss from dry deposition. For dry deposition, the average lifetime of ozone is $28 \mathrm{~h}\left(200 \mathrm{~m} / 0.002 \mathrm{~m} \mathrm{~s}^{-1}\right)$, and for chemical loss it is $12 \mathrm{~h}$. Both losses of $\mathrm{O}_{x}$ added together are about triple the observed time rate of change, and thus the physical and chemical losses are largely $(\sim 2 / 3)$ compensated for by vertical mixing. Because the RL consistently contains more ozone than the stable NBL, turbulent mixing will result in a transfer of ozone into the NBL. While $\mathrm{NO}_{2}$ is observed to be higher in the NBL than in the RL (by about 3-5 ppbv), it is a much smaller contribution to $\mathrm{O}_{x}\left(\mathrm{O}_{3}\right.$ is less than $\mathrm{NO}_{2}$ by anywhere from 10 to 20 ppbv.) Thus, vertical mixing at the top of the NBL, influenced by the strength of the LLJ, is inherently a source term of $\mathrm{O}_{x}$ to the lower NBL.

\subsection{Error analysis}

Here we estimate the uncertainties for each term in the budget equation and those for the resultant eddy diffusivities. The storage term error is computed by first taking the standard deviation of $1 \mathrm{~s}$ ozone measurements divided by the square root of the number of samples, then the standard error of the means for both the late-night and morning profiles are combined. This analysis is carried out in $20 \mathrm{~m}$ altitude bins separately and then averaged together because there is more uncertainty at lower altitudes due to fewer measurements. The advection term error is computed from the standard error of the slopes of the regression fit, with errors propagating for each of the four advection components for both the $u$ and $v$ components of wind. To compute the chemical loss error, the large uncertainty of the $\alpha$ coefficient must be taken into consideration. Based on our analysis concluding that all channels of nitrate loss are probably non-negligible, we infer that $\alpha$ is between 0.5 and 2.5 with a $95 \%$ confidence interval. Thus, 1 standard error for the $\alpha$ coefficient is about 0.5 . An error propagation is then carried out for each $20 \mathrm{~m}$ altitude bin using the standard deviations of the $\mathrm{O}_{3}$ and $\mathrm{NO}_{2}$ measurements divided by the square root of the sample size. As previously stated, the estimated standard errors of the NBL height and surface deposition of ozone are taken to be $100 \mathrm{~m}$ and $0.1 \mathrm{~cm} \mathrm{~s}^{-1}$, respectively. The surface ozone standard error is computed as the standard deviation of the aircraft measurements divided by the square root of the sample size, and the vertical $\mathrm{O}_{x}$ gradient uncertainty is computed by the standard error of the regression slope. The uncertainties in the vertical mixing, deposition flux, and diffusivity values can then be computed by standard error propagation. The resultant relative error estimates of the nighttime diffusivities are about $50 \%$, and errors of this order seem reasonable based on a technique that assumes the closure of four independently measured terms. Past studies using similar airborne budgeting methods have estimated relative uncertainties ranging from $15 \%$ to $75 \%$ (Conley et al., 2011; Faloona et al., 2009; Kawa and Pearson, 1989; Trousdell et al., 2016).

\subsection{The Fresno eddy and $L L J$}

The formation of the Fresno eddy begins when the daytime northwesterly valley wind continues into the late evening, decoupling from the surface and forming an LLJ (Davis, 2000). The Tehachapi Mountains will typically topographically block the flow of the LLJ (Lin and Jao, 1995). The eddy is formed during the hours before dawn when this northwesterly flow interacts with southeasterly nocturnal downslope flow coming from the high southern Sierra Nevada Mountains, although there is some question as to the extent to which the southeasterly flow observed in the morning hours is merely the result of a topographic deflection and recirculation of the nocturnal jet. The Coriolis force helps to circulate this flow; however, a mesoscale low is not thought to develop (Bao et al., 2008; Lin and Jao, 1995). We note that the valley flow peaks around midnight, while the katabatic drainage flow peaks near dawn, so these two components of the Fresno eddy are not time coherent. The initial northwesterly wind and a topographic blockage are both critical for determining whether or not the eddy will form on a given night (Lin and Jao, 1995).

One complicating factor for our scalar budget analysis is the influence that this eddy will have on our measurements of advection. If an eddy is recirculating a scalar quantity, using a simple linear fit model as we did in Sect. 2.2.3 to estimate advection would be questionable, especially if the flight area only covered a small portion of the larger mesoscale circulation. Zhong et al. (2004) use a series of $915 \mathrm{MHz}$ RASSs to analyze low-level winds in the SSJV. Their Fig. 4 shows that at night, the northwesterly LLJ is formed in the SJV, and a weak katabatic southerly flow is observed in the foothills to the east at the Trimmer site. As the night progresses, the 


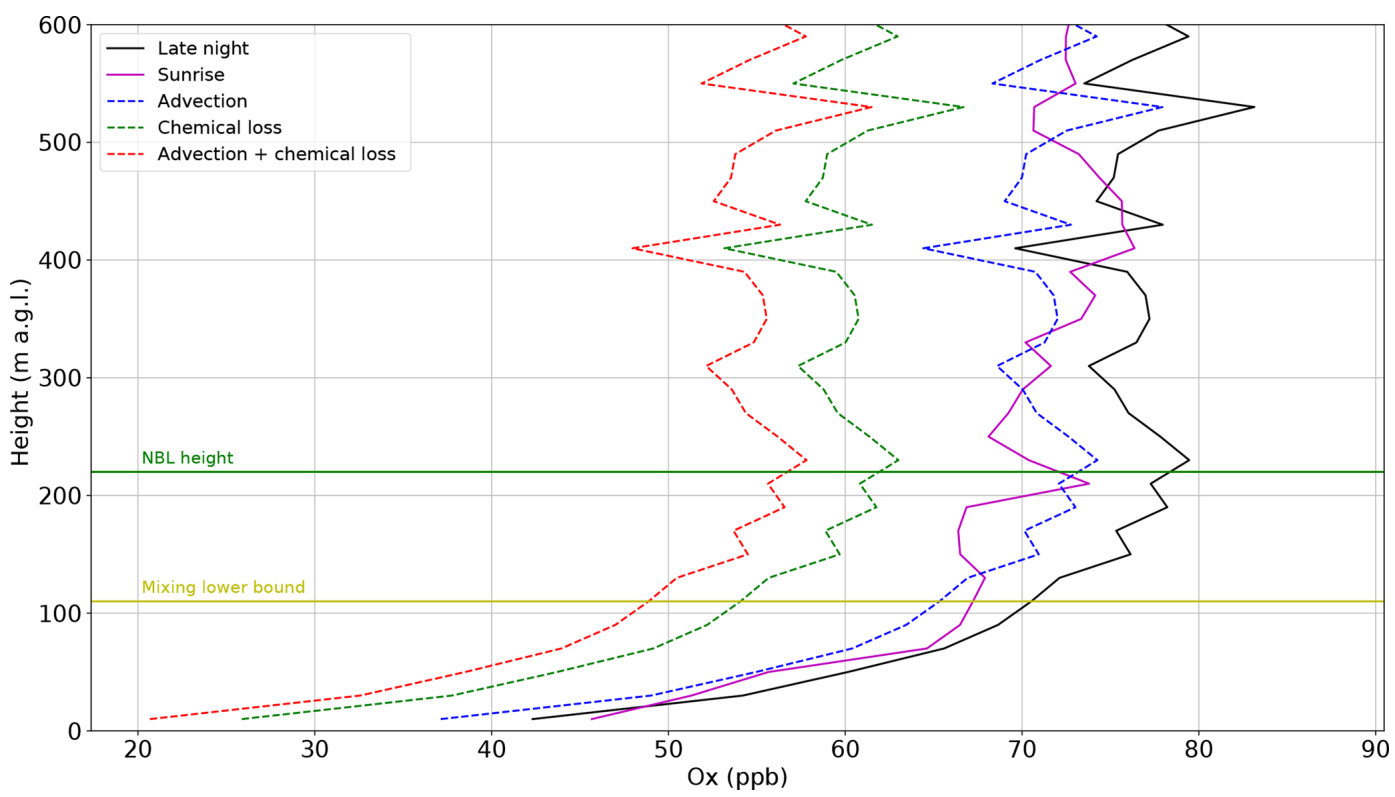

Figure 6. $\mathrm{O}_{x}$ profiles from 4 June 2016 overnight analysis, NBL height (green line), and lower bound to vertical mixing gradient (yellow line). The solid lines are observations and the dashed lines are calculated based on expected changes due to horizontal advection (blue), chemical loss (green), and the sum of the two (red).

Table 3. Results from the nocturnal scalar budget for all terms. Estimated error (see Sect. 3.2) in parenthesis.

\begin{tabular}{lrrrrrr}
\hline Flight date & $\begin{array}{r}\text { Storage } \\
\mathrm{ppbh}^{-1}\end{array}$ & $\begin{array}{r}\text { Advection } \\
\mathrm{ppbh}^{-1}\end{array}$ & $\begin{array}{r}\text { Chemical loss } \\
\mathrm{ppbh}^{-1}\end{array}$ & $\begin{array}{r}\text { Vertical mixing } \\
\mathrm{ppbh}^{-1}\end{array}$ & $\begin{array}{r}\text { Deposition } \\
\mathrm{ppbh}^{-1}\end{array}$ & $\begin{array}{r}\text { Eddy diffusivity } \\
\mathrm{m}^{2} \mathrm{~s}^{-1}\end{array}$ \\
\hline 9 Sep 2015 & $-2.3(0.2)$ & $-3.2(0.2)$ & $-3.6(1.3)$ & $5.1(3.1)$ & $-0.6(0.4)$ & $3.0(1.3)$ \\
12 Sep 2015 & $-0.2(0.2)$ & $-0.0(0.1)$ & $-2.9(0.9)$ & $4.0(5.2)$ & $-1.4(1.3)$ & $3.5(3.0)$ \\
3 Jun 2016 & $-0.7(0.1)$ & $0.3(0.2)$ & $-1.5(0.4)$ & $1.5(0.9)$ & $-1.0(0.6)$ & $2.9(1.4)$ \\
4 Jun 2016 & $-0.5(0.2)$ & $-0.6(0.1)$ & $-1.9(0.6)$ & $3.2(2.0)$ & $-1.2(0.8)$ & $2.9(1.2)$ \\
29 Jun 2016 & $-1.3(0.2)$ & $-1.0(0.1)$ & $-2.2(0.6)$ & $3.4(3.1)$ & $-1.6(1.3)$ & $2.0(1.1)$ \\
25 Jul 2016 & $-1.2(0.2)$ & $0.6(0.2)$ & $-2.7(0.8)$ & $2.0(1.5)$ & $-1.2(0.9)$ & $1.1(0.6)$ \\
26 Jul 2016 & $-1.4(0.2)$ & $0.2(0.2)$ & $-2.2(0.8)$ & $1.3(1.0)$ & $-0.7(0.4)$ & $1.5(1.1)$ \\
13 Aug 2016 & $-1.4(0.2)$ & $-0.3(0.2)$ & $-3.4(1.1)$ & $4.1(3.6)$ & $-1.8(1.5)$ & $2.3(1.2)$ \\
15 Aug 2016 & $-1.1(0.1)$ & $0.6(0.2)$ & $-2.5(0.9)$ & $1.8(1.3)$ & $-0.9(0.6)$ & $2.6(1.6)$ \\
16 Aug 2016 & $-1.9(0.2)$ & $-0.1(0.1)$ & $-3.0(1.1)$ & $2.3(1.9)$ & $-1.0(0.7)$ & $2.2(1.4)$ \\
17 Aug 2016 & $-2.0(0.2)$ & $0.1(0.1)$ & $-3.7(1.4)$ & $2.8(2.5)$ & $-1.2(0.9)$ & $1.5(1.0)$ \\
18 Aug 2016 & $-1.6(0.2)$ & $0.5(0.2)$ & $-3.1(1.2)$ & $2.2(2.0)$ & $-1.2(0.9)$ & $1.9(1.3)$ \\
\hline Average & $-1.30(0.18)$ & $-0.24(0.16)$ & $-2.73(0.93)$ & $2.81(2.34)$ & $-1.15(0.86)$ & $2.28(1.35)$ \\
\hline SD & 0.59 & 1.00 & 0.66 & 1.12 & 0.33 & 0.69 \\
\hline
\end{tabular}

eddy becomes more coherent as the northwesterly jet relaxes, while the southerly flow strengthens and expands westward. After daybreak, the eddy appears to deform and disintegrate, with much of the SSJV experiencing a strong southerly wind.

This pattern is roughly consistent with our aircraft observations, suggesting the presence of a Fresno eddy during our flights. An analysis of the average wind vectors and their consistency for all nocturnal and morning flights in the approximate NBL (0-300 m a.g.1.) and RL (300-700 m a.g.l.) is shown in Fig. 7. The wind consistency is defined as the ratio of the vector-averaged wind speed to the magnitudeaveraged wind speed, with values close to 1 indicating a consistent wind direction (Stewart et al., 2002; Zhong et al., 2004). The nocturnal LLJ can clearly be seen to fill most of the SSJV in both the NBL and RL. In the morning RL, there is localized consistent southerly flow closest to the foothills, some of which may be regarded as surprisingly strong. The lower-level winds in the morning are consistent with the deformed eddy. We note that caution should be exercised in directly comparing our flight data to the analysis 

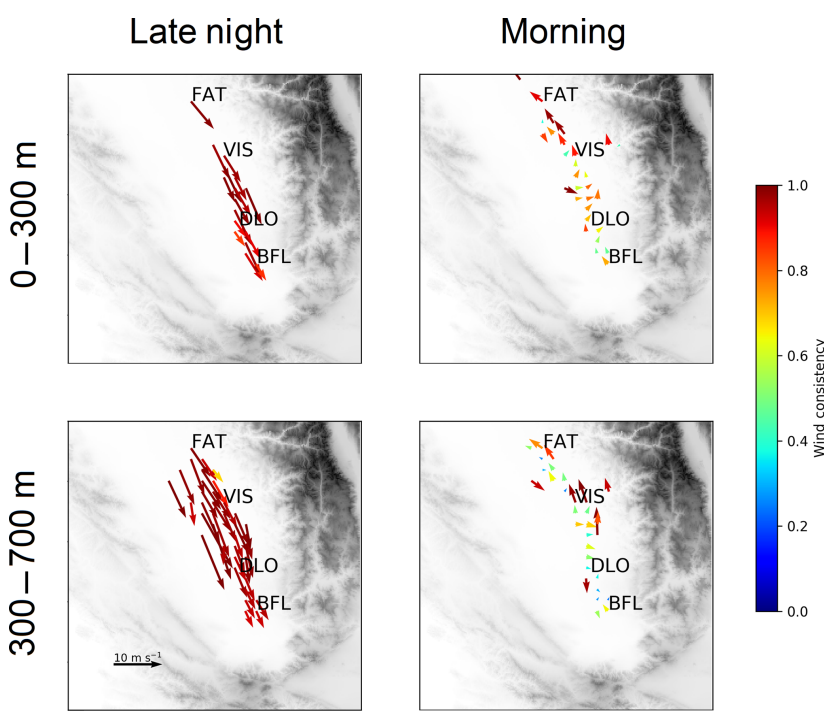

Figure 7. Wind consistency for late-night flights and morning flights in the NBL (0-300 m) and the RL (300-700 m).

from Zhong et al. (2004) as our flights specifically targeted high-ozone events, which we based primarily on high temperature stagnation conditions (see Fig. 5). Thus, the synoptic and mesoscale conditions during our flights may be systematically different from the climatological norms presented in Zhong et al. (2004).

From this analysis, we conclude that it is likely that our dataset captures the bulk of the dominant flow (and thus advection) on both the late-night and morning flights, which are averaged and interpolated. The average advection term for the 12 nights presented is $-0.24 \mathrm{ppbh}^{-1}$, which is nearly an order of magnitude smaller than the chemical loss and storage terms. The small average contribution from advection is consistent with previous findings from daytime scalar budgets performed over the oceans (Conley et al., 2011; Faloona et al., 2009) and in the SJV (Trousdell et al., 2016) and what might be expected in the presence of a recirculating eddy. Lastly, it is noted that individually adjusting each flight to have an advection term of zero (to assume full eddy recirculation) results in only a $3 \%$ change to the average of the diffusivity values, which further supports the idea that the influence of advection on our scalar budget analysis is minimal.

Since the LLJ is hypothesized to contribute to the variability of maximum daytime ozone concentration, we explored the synoptic patterns that are associated with differing strengths of the LLJ. A total of 7 years of data (20102016) from the $915 \mathrm{MHz}$ sounder located in Visalia, CA, are compiled to obtain the LLJ speed and the height at which it was observed. For this analysis, we define the nocturnal LLJ speed as the maximum hourly averaged wind speed observed below $1000 \mathrm{~m}$ averaged in $100 \mathrm{~m}$ vertical bins from 23:00 to 07:00 PST, specifically during the summer months (defined here as 1 June-30 September). The $1000 \mathrm{~m}$ cutoff is used to ensure that the wind maximum captured is related to the LLJ at the top of the NBL rather than free-tropospheric wind. Using this definition, the LLJ had an average height of $340 \mathrm{~m}$, an average speed of $9.9 \mathrm{~m} \mathrm{~s}^{-1}\left(\sigma=3.1 \mathrm{~m} \mathrm{~s}^{-1}\right)$, and a typical peak timing around 23:00 PST. The $700 \mathrm{mb}$ level corresponds to approximately $3000 \mathrm{~m}$, well above the Pacific Coast Range but approximately in line with the top of the southern Sierras.

To analyze possible synoptic influences on the jet strength, daily average synoptic charts from the North American Regional Reanalysis (NARR) are created in Figs. 8 and 9 for days when the LLJ strength was less than $7 \mathrm{~m} \mathrm{~s}^{-1}(N=147$ nights) and greater than $12 \mathrm{~m} \mathrm{~s}^{-1}(N=165$ nights). Both the strong and weak low-level jets show a climatological trough pattern, but the mean trough axis is situated about $100 \mathrm{~km}$ to the east for the strong cases (Fig. 8b). We also note that the pressure gradient is at least twice as strong for the stronger low-level jets and that the synoptic pattern of the weak jets favors a southerly geostrophic wind aloft, which directly opposes the up-valley northwesterly thermally driven flow. We also find a positive correlation between the LLJ strength and the upwelling index $\left(r^{2}=0.3018, p<10^{-5}\right)$, calculated by NOAA's Pacific Fisheries Environmental Lab at $33^{\circ} \mathrm{N}, 119^{\circ} \mathrm{W}$ (https://www.pfeg.noaa.gov/products/PFEL/ modeled/indices/upwelling/NA/upwell_menu_NA.html, last access: 8 August 2018). The indices are primarily driven by the strength and position of the North Pacific High, which, when strong, acts to push the $700 \mathrm{mb}$ trough farther eastward, as seen in Fig. 8b, and is associated with lower sea surface temperatures and thus enhanced thermal forcing of the coupled sea breeze and valley wind. These findings are consistent with the Lin and Jao (1995) modeling study that showed that the Fresno eddy (and associated LLJ) did not form when the synoptic flow over the coastal range was westerly. Beaver and Palazoglu (2009) found that maximum daily $8 \mathrm{~h}$ average ozone (MDA8) exceedances were more frequent in the central and southern San Joaquin Valley when an offshore ridge or onshore high was present, consistent with Fig. 8a. The results of our study suggest that this may be at least partially explained by the presence of a weaker LLJ under those synoptic conditions.

Although the LLJ and Fresno eddy are not synonymous, we propose that the northwesterly LLJ could be the dominant feature of the eddy's northerly flow component. This leads to an important question about the role of the Fresno eddy in modulating the daily ozone peak. Beaver and Palazoglu (2009) purport that ozone levels in the central SJV are particularly high on days when the morning southerly wind at Parlier, a site about midway between Fresno and Visalia, is strong, concluding that recirculation from the downslope branch of the Fresno eddy significantly controls the day's buildup of ozone. However, mixing induced by LLJs in other parts of the world has been shown to decrease ozone levels the following day (Hu et al., 2013; Neu, 1995). Thus, it may be the case that a Fresno eddy associated with a particularly 
strong LLJ may decrease ozone the following day if the recirculation of ozone and its precursors does not overcompensate for overnight losses due to vertical mixing down to the surface. We suggest that the Fresno eddy, when present, will act to recirculate pollutants regardless of the strength of the LLJ. That is, a stronger eddy will not recirculate pollutants any more than a weaker one will. Thus, the nighttime dynamical conditions that will lead to the greatest ozone levels the following day may consist of a Fresno eddy just coherent enough to effectively recirculate pollutants, but without an associated LLJ so strong as to deplete the RL ozone by vertical mixing. There is currently no established link in the literature between the Fresno eddy and LLJ strength. Thus, future research should investigate which of these two nocturnal mechanisms (recirculation from the eddy or RL depletion by vertical mixing) will dominate the ozone budget on any given night, taking into consideration the different possible structures and timing of the Fresno eddy as well as the synoptic conditions that engender them.

In addition to the synoptic patterns discussed above, slightly lower surface temperatures across the entire region are observed during stronger LLJs (Fig. 9). This could either be a consequence of the synoptic flow (southerly geostrophic flow will generally bring warm air advection) or itself be an underlying precursor to the LLJ. In the latter case, a $\sim 2 \mathrm{~K}$ greater temperature difference between the delta region and the SSJV for strong LLJs (seen in Fig. 9) will lead to more up-valley thermal forcing, resulting in stronger winds that decouple from the surface at night. The higher temperatures associated with the weak nocturnal jets may make for a twofold mechanism for high ozone: the high temperatures either cause increased photochemical production or result from increased meteorological stagnation, and a lack of mixing overnight induced by the LLJ causes less depletion of the RL ozone. Warmer nights may also result in less dry deposition of $\mathrm{O}_{x}$ through stomatal pores.

\subsection{Vertical mixing and next-day ozone}

As seen in Fig. 4, the average LLJ height is $200-400 \mathrm{~m}$, which approximately corresponds to the average NBL depth. Likely due to the shear induced by the LLJ, turbulence is seen to be vigorous at night with TKE values about $50 \%$ of daytime values during convective conditions. Further, TKE increases toward the surface, a condition that Banta et al. (2006) refer to as a "traditional" stable boundary layer. As previously mentioned, the physical significance of turbulent mixing overnight in relation to SJV air pollution remains somewhat of an open question. On the one hand, Beaver and Palazoglu (2009) suggest that a stronger Fresno eddy circulation is associated with higher ozone pollution. On the other hand, greater coupling between the NBL and RL, induced by turbulence generated from the LLJ, could reduce the amount of ozone stored in the RL reservoir, rendering cleaner air the following day. To test this hypothesis, the relationship be- tween the eddy diffusivity values found in our study and regional mean surface ozone from the CARB network is analyzed.

The thermals generated by solar heating after sunrise initiate a fumigation process whereby as the daytime boundary layer develops, the ozone that was in the RL is mixed downward. The change in surface ozone concentration $\left(\mathrm{d}\left[\mathrm{O}_{3}\right] / \mathrm{d} t\right)$ due to fumigation peaks at around 08:00 PST and continues until about 10:00. The relationship between our estimated eddy diffusivities and ozone during the fumigation period is strongest at 10:00 PST, after the bulk of the fumigation has occurred $\left(r^{2}=0.29, p=0.07\right)$. A negative correlation between eddy diffusivities and the maximum $1 \mathrm{~h}$ ozone, $24 \mathrm{~h}$ average ozone, and MDA8 was also found, with the strongest relationship for the MDA8 $\left(r^{2}=0.46, p=0.015\right)$, as shown in Fig. 10. This supports our hypothesis that stronger NBL turbulence is associated with lower ozone the following day.

Because this analysis consisted of only 12 flights, we explored a larger dataset that might support the hypothesis that a stronger LLJ reduces ozone the following day. A total of 7 years of LLJ speeds obtained from the Visalia sounder from 2010-2016 are combined with the CARB surface network ozone monitoring site at Visalia N Church St $\left(36.3325^{\circ} \mathrm{N}\right.$, $119.2908^{\circ} \mathrm{W} ; 30 \mathrm{~m}$ elevation) for analysis. Only calendar days 152 through 273 (June-September) are included. The LLJ, hypothesized to be the main contribution to the variability in overnight mixing between the RL and NBL, is compared with MDA8 observed the following day, as shown in Fig. 11. It can be seen that a stronger nocturnal LLJ is correlated, albeit weakly, with lower ozone the following day $\left(r^{2}=0.181, p<10^{-5}\right)$. A single outlier was removed for which the LLJ exceeded $25 \mathrm{~m} \mathrm{~s}^{-1}$. This overall relationship supports our hypothesis that the LLJ leads to stronger mixing, which in turn leads to more RL ozone depletion.

The physical processes of $\mathrm{RL} \mathrm{O}_{x}$ depletion once it mixes down into the NBL represent a further question. The main destruction processes of $\mathrm{O}_{x}$ in the NBL are chemical loss and dry deposition. One possibility is that surface sources of $\mathrm{NO}_{2}$ contribute to the excess nocturnal chemical depletion of $\mathrm{O}_{x}$ in the NBL. However, the chemical loss of $\mathrm{O}_{x}$ is not thought to vary significantly between the RL and NBL because the increase in $\mathrm{NO}_{2}$ in the NBL is compensated for by the decrease in $\mathrm{O}_{3}$ (see Fig. 4), although this assumes that there are no other chemical differences that alter the reaction fate of nitrate (i.e., $\alpha$ in Eq. 1). Another possibility is that the deposition velocity of ozone may be enhanced by a reduction of aerodynamic resistance under a stronger LLJ. The dry deposition of any gas may be characterized by a series of resistances (Wesely, 1989):

$v_{\mathrm{d}}=\frac{1}{r_{\mathrm{a}}+r_{\mathrm{b}}+r_{\mathrm{c}}}$,

where $r_{\mathrm{a}}$ is the aerodynamic resistance, $r_{\mathrm{b}}$ is the viscous sub-layer resistance, and $r_{\mathrm{c}}$ is the surface (or canopy) resistance. Figure 4 in Padro (1996) suggests that for ozone 


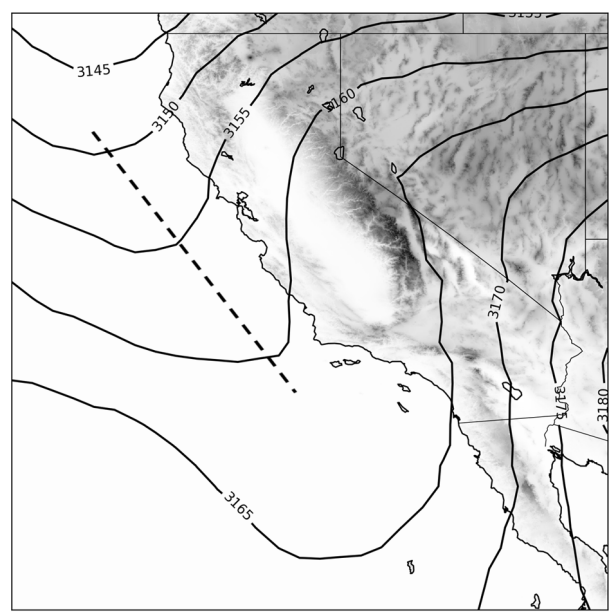

(a)

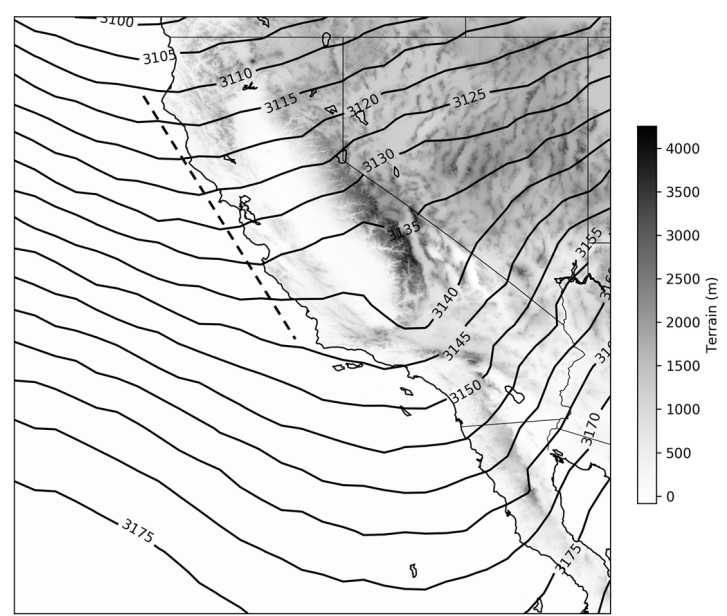

(b)

Figure 8. North American Regional Reanalysis $700 \mathrm{mb}$ geopotential height $(\mathrm{m})$ for low-level jet speeds less than $7 \mathrm{~m} \mathrm{~s} \mathrm{~s}^{-1}$ (a) and greater than $12 \mathrm{~m} \mathrm{~s}^{-1}$ (b).

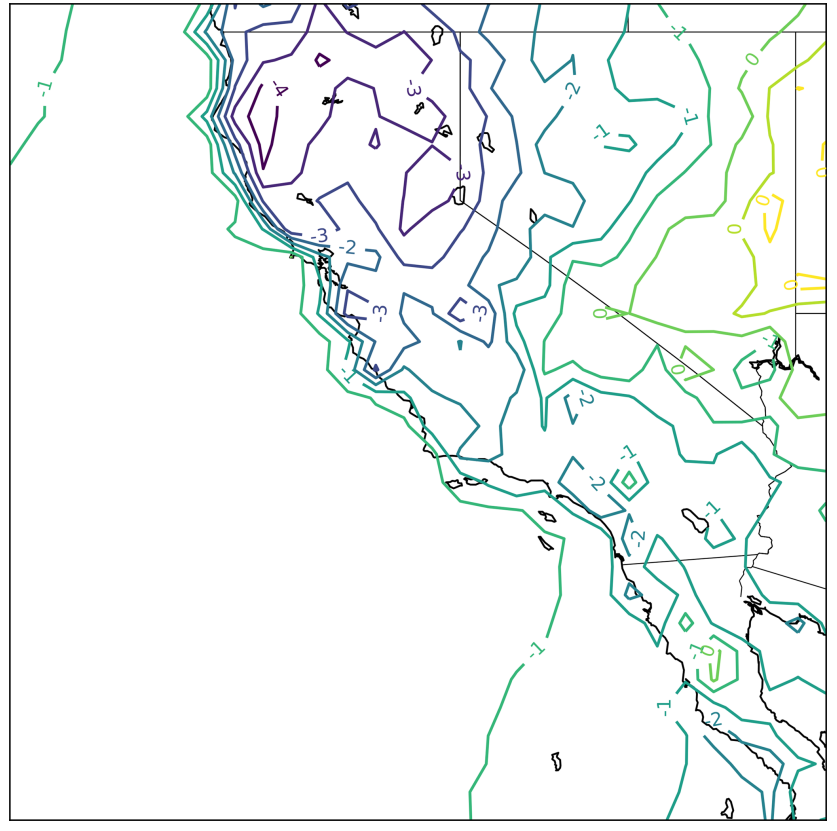

Figure 9. North American Regional Reanalysis $2 \mathrm{~m}$ air temperature $\left({ }^{\circ} \mathrm{C}\right)$ difference between cases in which the low-level jet speed exceeds $12 \mathrm{~m} \mathrm{~s}^{-1}$ and cases in which it is below $7 \mathrm{~m} \mathrm{~s}^{-1}$ at 01:00 PST. Positive values indicate warmer surface temperatures for strong jets.

at night, $r_{\mathrm{a}} \sim r_{\mathrm{c}} \sim 250 \mathrm{~s} \mathrm{~m}^{-1}$. $r_{\mathrm{b}}$ is likely nonzero (Massman et al., 1994) but is typically several times smaller than the other resistances (Georgiadis et al., 1995; Pilegaard et al., 1998), so we assume that $r_{\mathrm{a}}=r_{\mathrm{b}}+r_{\mathrm{c}}=250 \mathrm{~s} \mathrm{~m}^{-1}$ to yield our estimated deposition velocity of $0.2 \mathrm{~cm} \mathrm{~s}^{-1}$. Combining an estimate of aerodynamic resistance due to mass transfer $\left(r_{\mathrm{a}}=U u_{*}^{-2}\right.$, where $u_{*}^{2}$ is the momentum flux) and parameterizing the momentum flux as a function of $10 \mathrm{~m}$ wind speed,

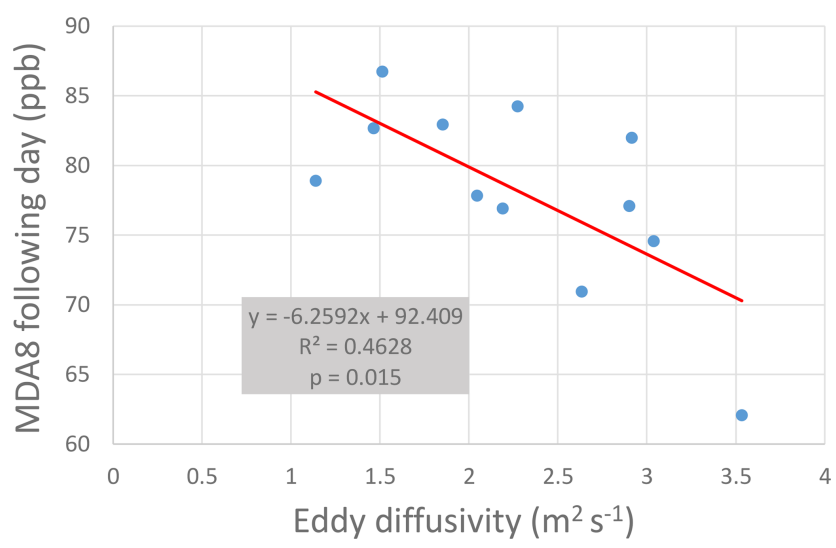

Figure 10. Correlation between overnight eddy diffusivity and maximum daily $8 \mathrm{~h}$ average ozone (MDA8) the following day. All values are averages of $11 \mathrm{CARB}$ surface network stations that are within the flight region.

$U_{10}$, and a drag coefficient $C_{\mathrm{D}}\left(u_{*}^{2}=C_{\mathrm{D}} U_{10}^{2}\right)$, we roughly approximate $r_{\mathrm{a}}$ as

$r_{\mathrm{a}} \sim \frac{1}{C_{\mathrm{D}} U_{10}}$

In the 7 years of LLJ data at Visalia, the $10 \mathrm{~m}$ wind speed is correlated with the jet strength $\left(r^{2}=0.309, p<10^{-5}\right)$. On average, $U_{10}$ was 1 for $5 \mathrm{~m} \mathrm{~s}^{-1}$ jets and 2.5 for $15 \mathrm{~m} \mathrm{~s}^{-1}$ jets. Assuming an average $U_{10}$ of $1.75 \mathrm{~m} \mathrm{~s}^{-1}$ and $r_{\mathrm{a}}$ of $250 \mathrm{~s} \mathrm{~m}^{-1}$, this would imply that $C_{\mathrm{D}} \sim 2.3 \times 10^{-3}$. A sensitivity analysis indicates that the difference in $U_{10}$ between strong and weak jets would result in an approximate $40 \%$ change in $v_{\mathrm{d}}$. We thus conclude that the LLJ likely plays a significant role in modulating the dry deposition rate, whereby a strong jet decreases $r_{\mathrm{a}}$ and thus increases $v_{\mathrm{d}}$, further contributing to a loss of ozone overnight. It is important to note that what we 


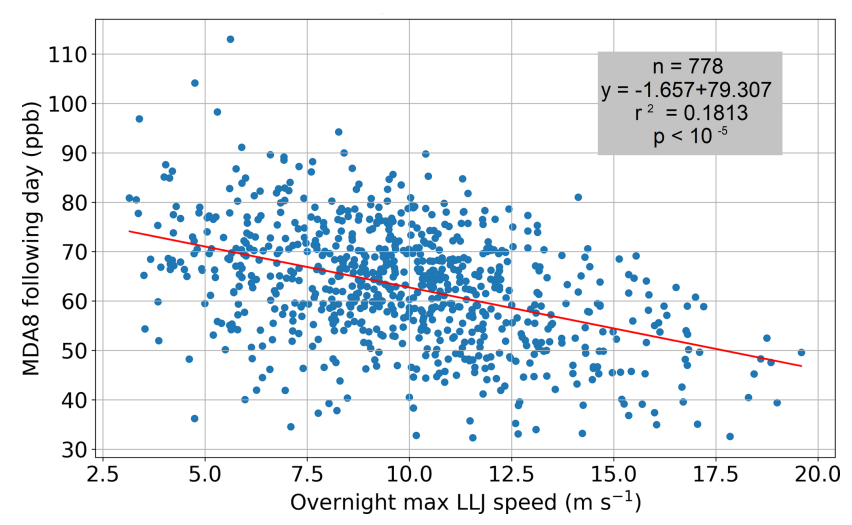

Figure 11. Correlation between nocturnal low-level jet speed and the following day's MDA8 in Visalia, CA, for calendar days 152273 from 2010 to 2016.

have presented is only a rough estimate of the variability of $r_{\mathrm{a}}$, and thus future studies should measure these parameters with more precision in order to better estimate the degree to which the LLJ can modulate dry deposition in the SJV. The average error of $K_{z}$ due to the uncertainty in $v_{\mathrm{d}}$ is calculated to be $\sim 0.50 \mathrm{~m}^{2} \mathrm{~s}^{-1}$ and is included in our error propagation analysis.

\subsection{Eddy diffusivity and other estimates of turbulence}

Here we attempt to build confidence in the eddy diffusivity estimates by analyzing additional metrics of turbulence. We find that nocturnally and spatially averaged TKE in the NBL ranges from 0.35 to $1.02 \mathrm{~m}^{2} \mathrm{~s}^{-2}$, which is very comparable to values obtained in other NBL studies (Banta et al., 2006; Lenschow et al., 1988). Table 1 shows the TKE, LLJ speed, and the ratio of the streamwise variance to LLJ speed $\left(\sigma_{\mathrm{u}} / U_{x}\right)$ for each night. The average value of $\sigma_{\mathrm{u}} / U_{x}$ in this study is 0.11 , approximately double what was reported in Banta et al. (2006). There is no detectable relationship between our calculated NBL TKE and eddy diffusivities, LLJ speed, or MDA8 the following day, which implies that the eddy diffusivities calculated from the scalar budget analysis may be a better measure of nocturnal mixing strength than TKE.

Our budget method of estimating turbulent dispersion differs from some other attempts that have been made for stably stratified environments. Clayson and Kantha (2008) applied a technique that had been previously used in oceans to the free troposphere, where turbulence is sparse and intermittent, much like in the NBL. Their method involves using high-resolution soundings to estimate a length scale of overturning eddies, known as the Thorpe scale (Thorpe, 2005), which is then used to obtain estimates of turbulent dissipation rate and subsequently eddy diffusivity. This is done by relating the Thorpe scale to the Ozmidov scale, whereby if the Brunt-Väisälä frequency $\left(N_{\mathrm{BV}}\right)$ is known, the TKE dis- sipation rate $(\varepsilon)$ can be estimated. Eddy diffusivity can then be estimated as a product of the TKE dissipation and $N^{-2}$ :

$K_{z}=\gamma \varepsilon N_{\mathrm{BV}}^{-2}$

where $\gamma$ is the mixing efficiency, which can vary between 0.2 and 1 (Fukao et al., 1994). From the nocturnal power spectra (Fig. 1) we use a Kolmogorov fit to estimate $\varepsilon$, which is determined to be approximately $4.8 \times 10^{-6} \mathrm{~m}^{2} \mathrm{~s}^{-3}$ for the overall altitude range of our nighttime flights (surface to $\sim 3000 \mathrm{~m}$ ), but a median of $3.0 \times 10^{-4} \mathrm{~m}^{2} \mathrm{~s}^{-3}$ is observed in the NBL. Using the average NBL Brunt-Väisälä frequency of $0.023 \mathrm{~Hz}$, a mixing efficiency of 0.6 , and the median NBL $\varepsilon$ results in an eddy diffusivity of $0.34 \mathrm{~m}^{2} \mathrm{~s}^{-1}$, which is about 3 times smaller than the lower end of our range $\left(1.1-3.5 \mathrm{~m}^{2} \mathrm{~s}^{-1}\right)$. A recent study of vertical mixing based on scalar budgeting of radon-222 in the NBL by Kondo et al. (2014) estimated 7-day average overnight diffusivities of $0.05-0.13 \mathrm{~m}^{2} \mathrm{~s}^{-1}$, which are an order of magnitude below our estimates inferred from the $\mathrm{O}_{x}$ budget. However, Wilson (2004) conducted a meta-analysis of radar-based estimates of eddy diffusivity in the free troposphere, which is also a generally stable environment, and found a range of $0.3-3 \mathrm{~m}^{2} \mathrm{~s}^{-1}$. Pisso and Legras (2008) estimated diffusivities of about 0.5 in the lower stratosphere during Rossby-waveinduced intrusions of midlatitude air into the subtropical region. A modeling study by Hegglin et al. (2005) reports diffusivities of $0.45-1.1 \mathrm{~m}^{2} \mathrm{~s}^{-1}$ in the lower stratosphere with an average Brunt-Väisälä frequency of $0.021 \mathrm{~Hz}$, indicating a similar turbulent environment to ours. Finally, Lenschow et al. (1988) analyzed flight data in the NBL over rolling terrain in Oklahoma and found eddy diffusivities for heat $\left(K_{\mathrm{h}}\right)$ of $\sim 0.25 \mathrm{~m}^{2} \mathrm{~s}^{-1}$ for the upper half of the NBL and $\sim 1 \mathrm{~m}^{2} \mathrm{~s}^{-1}$ for the lower half. To our knowledge, the latter is the most comparable observational finding within the NBL to our range of diffusivities. Nevertheless, the variability in the reported values leads to the conclusion that vertical diffusivity in very stable environments is poorly understood, and further research is necessary to illuminate its phenomenology. More specifically, while it is possible that the diffusivity measurements in this study are biased high (e.g., due to overestimates of the chemical loss parameter $\alpha$ ), it is also possible that the LLJ and other mesoscale wind features of the complex terrain account for stronger nocturnal mixing in the SSJV compared to those in other stable environments.

Lastly, we estimate the BRN on each late-night flight within the NBL using $100 \mathrm{~m}$ bins to estimate wind shear. A range of Richardson numbers between 0.23 and 1.34 is obtained, and the estimates are seen to have a slight negative relationship with eddy diffusivities as illustrated in Fig. 12. The weak correlation is probably the result of the limited dataset coupled with the challenging nature of both the eddy diffusivity and BRN measurements. 


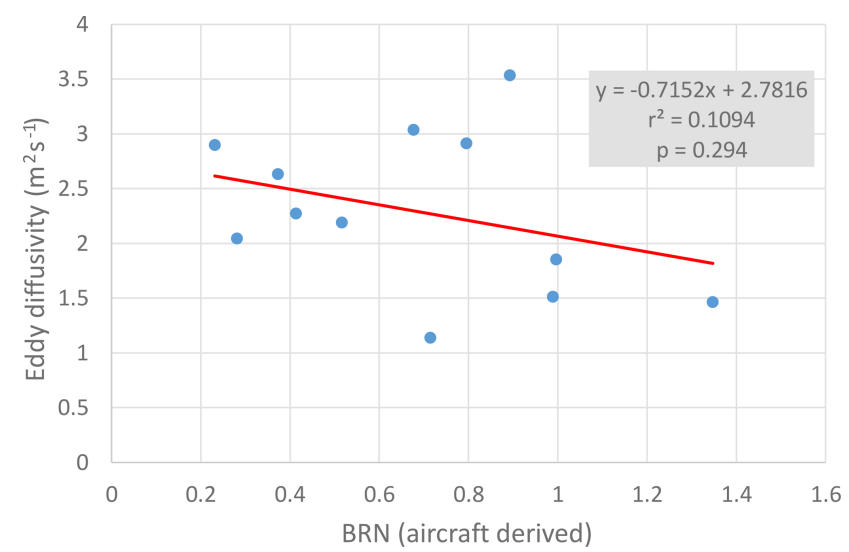

Figure 12. Eddy diffusivities and bulk Richardson numbers (BRNs) derived from aircraft observations.

\subsection{Nocturnal elevated mixed layers}

During the late-night flights in stable environments, the flight crew reported many patches of turbulence. While most of these subjective reports were during low approaches and thus likely attributable to wind shear between the LLJ and the surface, they noted that some patches corresponded to what appeared to be elevated mixed layers, i.e., layers of air in which virtual potential temperature was observed to decrease with height. These layers may be of special interest to our analysis of overnight mixing, since absolutely unstable layers of air generate turbulence and vertical mixing. The time series of all late-night flights was scanned for any period during which (1) the aircraft maintained an ascent (or descent) rate of at least $1.4 \mathrm{~m} \mathrm{~s}^{-1}$, and (2) during a given elevation span of at least $100 \mathrm{~m}$, a virtual potential temperature decrease with height was observed. The process was repeated for a thickness of at least $50 \mathrm{~m}$.

The locations of the layers greater than $50 \mathrm{~m}$ thickness, along with their elevation and lapse rate, are shown in Fig. 13. One feature of note is that the layers appear to be more prominent over urban areas, such as Fresno, Visalia, and Bakersfield. This may lead one to suspect that some of these layers are driven by an urban heating effect; however, this seems unlikely as the unstable layers appear mostly above the NBL wherein the communication with the surface is relatively rapid. Rather, the appearance of these layers clustering around urban areas may be the result of a flight sampling bias and thus may not be significant. Another feature worth noting is that more unstable layers are observed closer to the Tehachapi Pass. One possible explanation for this is that the katabatic flow down the mountain slopes detrains along the way and is carried over the valley by local advection before mixing with surrounding air. Given that these layers are found from near the bottom of the RL all the way up to $2.5 \mathrm{~km}$, it is possible that they contribute to the overnight mixing of $\mathrm{O}_{x}$ from the RL to the NBL by main-

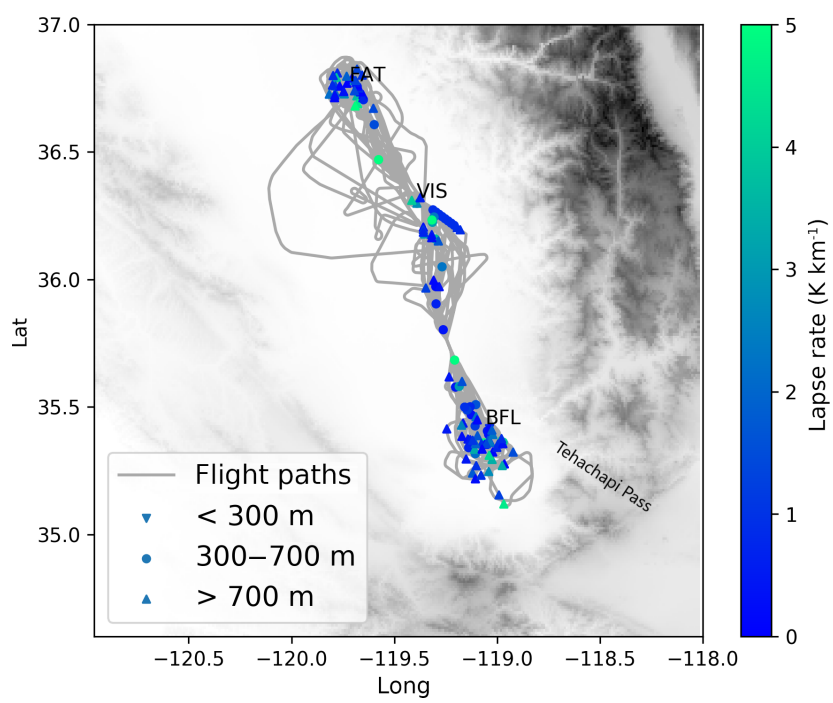

Figure 13. Detected nocturnal elevated mixed layers with at least $50 \mathrm{~m}$ thickness, with elevations shown.

taining a fairly well-mixed lower atmosphere over the valley. Further research, both observational and modeling based, is needed to explore this possibility.

The unstable layers are not found to have more TKE than the rest of the atmosphere. While this may reflect the limitations of the method used to estimate turbulence from this low-cost wind measurement system, it is consistent with the study by Cho et al. (2003) that found no relationship between turbulence and static stability in the free troposphere. Interestingly, their analysis of aircraft data collected over the $\mathrm{Pa}$ cific Ocean up to $8 \mathrm{~km}$ of altitude found unstable layers in $6 \%$ to $25 \%$ (depending on the layer thickness definition of 100 to $10 \mathrm{~m}$ ) of their profiles above the boundary layer (Cho et al., 2003). Because the aircraft moves more than 10 times faster horizontally than vertically during profiling, the observations of the elevated mixed layers may be an artifact of localized temperature gradients that are more prominent in the horizontal dimension. To confirm that this is not the case, we examined the wind quivers in the unstable layers along with the direction of the colder air. The cooler air was not systematically detected in any one direction, which supports the hypothesis that they are true vertical temperature gradients.

To analyze the stability, wind shear, and turbulence from a climatological standpoint, a July-August 2016 composite of the $915 \mathrm{MHz}$ Visalia sounder data is presented in Fig. 14. Even in the 2-month averages, some nocturnal unstable layers are detectable between 500 and $1500 \mathrm{~m}$, which further supports the existence of persistent elevated mixed layers that may contribute to the overnight mixing of pollutants in the lower troposphere over the valley. 
Visalia wind profiler July \& August 2016

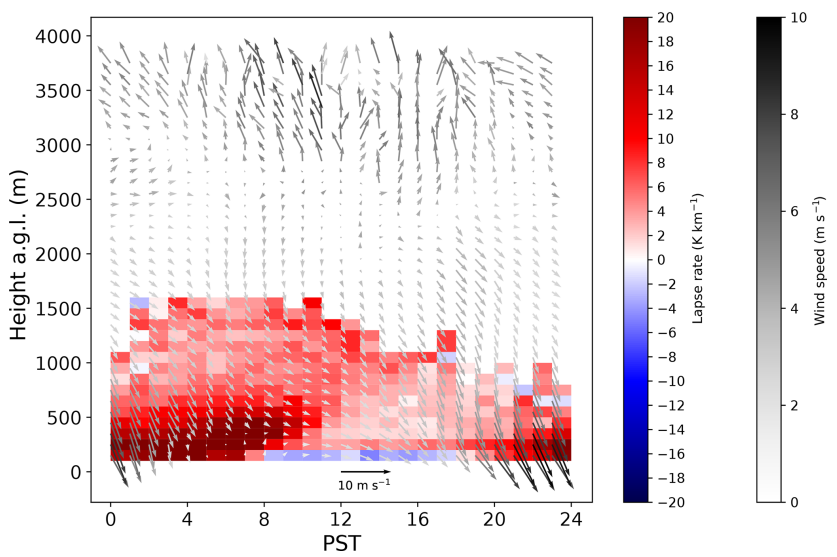

Figure 14. Stability and wind quivers for the Visalia $915 \mathrm{MHz}$ sounder, 1 July-31 August 2016.

\section{Conclusions}

We have demonstrated a method for performing a nocturnal $\mathrm{O}_{x}$ budget analysis using aircraft data and applied it to estimate the effects of turbulent mixing in the NBL, which can be used to help understand many air quality issues in the SJV. Inherently, eddy diffusivity estimates for any given night will have a large uncertainty due to the indirect nature of the measurement and the limited flight durations. However, the overall between-flight consistency and the correlations of the eddy diffusivities with both the Richardson number and surface ozone suggest that this method is informative. We obtain eddy diffusivity values between 1.1 and $3.5 \mathrm{~m}^{2} \mathrm{~s}^{-1}$, which are larger but approximately within the same order of magnitude of values that have been obtained from other studies in the free troposphere, lower stratosphere, and NBL. One limitation of our study is the lack of sample size, with only 12 pairs of overnight and morning flights. Nevertheless, we believe this study demonstrates the importance of focused flight strategies that measure the individual terms of the scalar budget equation and highlights the significant influence that synoptic and mesoscale meteorological conditions can have on the overnight destruction of ozone, thereby impacting the following day's peak concentrations.

The larger set of RASS and ARB surface network data from Visalia, CA, shows a correlation between LLJ speed and the MDA8 the following afternoon for summertime months, further suggesting a link between nocturnal mixing and the ensuing day's ozone levels. In particular, we note that 5 out of 6 days when the Visalia, CA, ozone MDA8 exceeded $90 \mathrm{ppb}$ were preceded by a weak LLJ $\left(<7 \mathrm{~m} \mathrm{~s}^{-1}\right)$. Similarly, the correlations between the aircraft-estimated eddy diffusivities and MDA8 the following day also suggest that vertical mixing in the NBL plays an important role in controlling ozone concentrations. While we cannot unequivocally infer a causal relationship in the data between a strong LLJ, stronger mixing, and reduced ozone levels, we propose a feasible process link with a stronger LLJ leading to greater mixing, which helps deplete the ozone reservoir in the RL by bringing it into the NBL overnight. There it is subject to dry deposition at the surface, wherein the deposition velocity itself may be modulated by the strength of the LLJ. Because the near-surface winds are accelerated by an overlying jet, a stronger LLJ reduces aerodynamic resistance, resulting in more efficient transport to surfaces and stomata where ozone can be taken up. Subsequently, when thermals begin to form after sunrise the following morning, there is less ozone to fumigate downward. We propose that the LLJ is a branch of the Fresno eddy, and the vertical mixing it induces may offset some of the next-day ozone enhancement that results from the eddy recirculating pollutants. Our findings highlight the crucial need for models to capture the LLJ and Fresno eddy with sufficient resolution, and policy makers may consider putting more stringent emission limitations on days when synoptic and mesoscale patterns appear to favor weak nocturnal mixing. Of course, in addition to nocturnal mixing, the photochemical production of ozone, as well as advection, will play a major role in the ultimate daytime peak ozone levels observed (Trousdell et al., 2016), which is likely why the correlation between nighttime turbulence and afternoon ozone is not always high.

The relative importance of these dynamical effects depends on the exact magnitude of the chemical loss of $\mathrm{O}_{x}$ overnight. We suggest that the ultimate fate of the $\mathrm{NO}_{3}$ radical plays a very important role in the $\mathrm{O}_{x}$ budget's chemical loss term, and thus it likely impacts the following day's maximum ozone concentration. The loss of the nitrate radical at night can occur from $\mathrm{N}_{2} \mathrm{O}_{5}$ hydrolysis, reaction with VOCs, or a very rapid reaction with small NO concentrations, and there is considerable uncertainty regarding which reactions dominate without concurrent measurements of $\mathrm{NO}_{3}, \mathrm{~N}_{2} \mathrm{O}_{5}$, and VOCs. Thus, the lifetime of $\mathrm{NO}_{3}$ can range from seconds to several minutes, which affects the chemical loss term in the scalar budget equation. It is therefore crucial to measure the lifetime of $\mathrm{NO}_{3}$ in future studies that analyze the NBL ozone or $\mathrm{O}_{x}$ budget. We also suggest more direct estimates of aerodynamic resistance and nocturnal ozone deposition at the surface by ground-based eddy covariance flux measurements in conjunction with future airborne studies.

Data availability. All of the aircraft data used in this analysis can be found at https://www.esrl.noaa.gov/csd/groups/csd3/ measurements/cabots/ (Caputi and Faloona, 2016; last access: 27 March 2019). NARR and Visalia $915 \mathrm{MHz}$ sounder data can be accessed from the Earth Science Research Laboratory website (https:// www.esrl.noaa.gov/, ESRL, 2018; last access: 10 September 2018), and CARB ground network data can be accessed from the CARB website (https://ww2.arb.ca.gov/, ARB, 2018; last access: 27 March 2018). The data can also be obtained by contacting the PI. 
Author contributions. IF designed the research study and DC, JS, and SC carried it out. DC and SC designed the scalar budget code and DC carried out the analysis. Other analyses were performed by DC, IF, JS, NF, and JT. DC prepared and submitted the paper.

Competing interests. The authors declare that they have no conflict of interest.

Acknowledgements. This project was supported by a grant sponsored by the California Air Resources Board, Research Division contract no. 14-308. We thank Steven S. Brown, William P. Dube, and Nick Wagner of the NOAA Chemical Sciences Division, Allen Goldstein of the University of California at Berkeley, and Drew Gentner of Yale University for freely sharing their data from the CalNex mission. We also thank Laura Bianco of the NOAA Physical Sciences Division for sharing the Chowchilla boundary layer height data. Ian Faloona was supported in part by the California Agricultural Experiment Station, Hatch project CA-D-LAW-2229H.

Review statement. This paper was edited by Robert Harley and reviewed by two anonymous referees.

\section{References}

Aneja, V. P., Mathur, R., Arya, S. P., Li, Y., Murray, G. C., and Manuszak, T. L.: Coupling the Vertical Distribution of Ozone in the Atmospheric Boundary Layer, Environ. Sci. Technol., 34, 2324-2329, https://doi.org/10.1021/es990997+, 2000.

ARB: California Air Resources Board, Air Quality Data (PST) Query Tool, available at: https://ww2.arb.ca.gov/, last access: 27 March 2018.

Arey, J., Corchnoy, S. B., and Atkinson, R.: Emission of linalool from Valencia orange blossoms and its observation in ambient air, Atmos. Environ., 25, 1377-1381, https://doi.org/10.1016/0960-1686(91)90246-4, 1991.

Atkinson, R. and Arey, J.: Atmospheric Chemistry of Biogenic Organic Compounds, Acc. Chem. Res., 31, 574-583, https://doi.org/10.1021/ar970143z, 1998.

Atkinson, R., Baulch, D. L., Cox, R. A., Crowley, J. N., Hampson, R. F., Hynes, R. G., Jenkin, M. E., Rossi, M. J., Troe, J., and IUPAC Subcommittee: Evaluated kinetic and photochemical data for atmospheric chemistry: Volume II - gas phase reactions of organic species, Atmos. Chem. Phys., 6, 3625-4055, https://doi.org/10.5194/acp-6-3625-2006, 2006.

Banta, R. M., Newsom, R. K., Lundquist, J. K., Pichugina, Y. L., Coulter, R. L., and Mahrt, L.: Nocturnal Low-Level Jet Characteristics Over Kansas During Cases-99, Bound.-Lay. Meteorol., 105, 221-252, https://doi.org/10.1023/A:1019992330866, 2002.

Banta, R. M., Pichugina, Y. L., and Brewer, W. A.: Turbulent Velocity-Variance Profiles in the Stable Boundary Layer Generated by a Nocturnal Low-Level Jet, J. Atmos. Sci., 63, 27002719, https://doi.org/10.1175/JAS3776.1, 2006.

Bao, J.-W., Michelson, S. A., Persson, P. O. G., Djalalova, I. V., and Wilczak, J. M.: Observed and WRF-Simulated Low-Level
Winds in a High-Ozone Episode during the Central California Ozone Study, J. Appl. Meteor. Climatol., 47, 2372-2394, https://doi.org/10.1175/2008JAMC1822.1, 2008.

Beaver, S. and Palazoglu, A.: Influence of synoptic and mesoscale meteorology on ozone pollution potential for San Joaquin Valley of California, Atmos. Environ., 43, 1779-1788, https://doi.org/10.1016/j.atmosenv.2008.12.034, 2009.

Bianco, L., Djalalova, I. V., King, C. W., and Wilczak, J. M.: Diurnal Evolution and Annual Variability of Boundary-Layer Height and Its Correlation to Other Meteorological Variables in California's Central Valley, Bound.-Lay. Meteorol., 140, 491-511, https://doi.org/10.1007/s10546-011-9622-4, 2011.

Brown, S. S., Stark, H., Ryerson, T. B., Williams, E. J., Nicks, D. K., Trainer, M., Fehsenfeld, F. C., and Ravishankara, A. R.: Nitrogen oxides in the nocturnal boundary layer: Simultaneous in situ measurements of $\mathrm{NO}_{3}, \mathrm{~N}_{2} \mathrm{O}_{5}, \mathrm{NO}_{2}, \mathrm{NO}$, and $\mathrm{O}_{3}$ : NOCTURNAL NITROGEN OXIDES, J. Geophys. Res.-Atmos., 108, 4299, https://doi.org/10.1029/2002JD002917, 2003.

Brown, S. S., Neuman, J. A., Ryerson, T. B., Trainer, M., Dubé, W. P., Holloway, J. S., Warneke, C., de Gouw, J. A., Donnelly, S. G., Atlas, E., Matthew, B., Middlebrook, A. M., Peltier, R., Weber, R. J., Stohl, A., Meagher, J. F., Fehsenfeld, F. C., and Ravishankara, A. R.: Nocturnal odd-oxygen budget and its implications for ozone loss in the lower troposphere, Geophys. Res. Lett., 33, L08801, https://doi.org/10.1029/2006GL025900, 2006.

Brown, S. S., Dubé, W. P., Osthoff, H. D., Wolfe, D. E., Angevine, W. M., and Ravishankara, A. R.: High resolution vertical distributions of $\mathrm{NO}_{3}$ and $\mathrm{N}_{2} \mathrm{O}_{5}$ through the nocturnal boundary layer, Atmos. Chem. Phys., 7, 139-149, https://doi.org/10.5194/acp-7139-2007, 2007.

Caputi, D. and Faloona, I.: CABOTS 2016 UC Davis / Scientific Aviation Data, available at: https://www.esrl.noaa.gov/csd/ groups/csd3/measurements/cabots/ (last access: 27 March 2019), 2016.

Cho, J. Y. N.: Characterizations of tropospheric turbulence and stability layers from aircraft observations, J. Geophys. Res., 108, 8784, https://doi.org/10.1029/2002JD002820, 2003.

Clayson, C. A. and Kantha, L.: On Turbulence and Mixing in the Free Atmosphere Inferred from High-Resolution Soundings, J. Atmos. Ocean. Technol., 25, 833-852, https://doi.org/10.1175/2007JTECHA992.1, 2008.

Conley, S. A., Faloona, I. C., Lenschow, D. H., Campos, T., Heizer, C., Weinheimer, A., Cantrell, C. A., Mauldin, R. L., Hornbrook, R. S., Pollack, I., and Bandy, A.: A complete dynamical ozone budget measured in the tropical marine boundary layer during PASE, J. Atmos. Chem., 68, 55-70, https://doi.org/10.1007/s10874-011-9195-0, 2011.

Conley, S. A., Faloona, I. C., Lenschow, D. H., Karion, A., and Sweeney, C.: A Low-Cost System for Measuring Horizontal Winds from Single-Engine Aircraft, J. Atmos. Ocean. Technol., 31, 1312-1320, https://doi.org/10.1175/JTECH-D-13-00143.1, 2014.

Conzemius, R. and Fedorovich, E.: Bulk Models of the Sheared Convective Boundary Layer: Evaluation through Large Eddy Simulations, J. Atmos. Sci., 64, 786-807, https://doi.org/10.1175/JAS3870.1, 2007.

Dabdub, D., DeHaan, L. L., and Seinfeld, J. H.: Analysis of ozone in the San Joaquin Valley of California, Atmos. Environ., 33, 25012514, https://doi.org/10.1016/S1352-2310(98)00256-8, 1999. 
Davis, P. A.: Development and mechanisms of the nocturnal jet, Meteorol. Appl., 7, 239-246, 2000.

ESRL: Physical Sciences Division, Climate Analysis and Plotting Tools, available at: https://www.esrl.noaa.gov/, last access: 10 September 2018.

Faloona, I., Conley, S. A., Blomquist, B., Clarke, A. D., Kapustin, V., Howell, S., Lenschow, D. H., and Bandy, A. R.: Sulfur dioxide in the tropical marine boundary layer: dry deposition and heterogeneous oxidation observed during the Pacific Atmospheric Sulfur Experiment, J. Atmos. Chem., 63, 13-32, https://doi.org/10.1007/s10874-010-9155-0, 2009.

Fukao, S., Yamanaka, M. D., Ao, N., Hocking, W. K., Sato, T., Yamamoto, M., Nakamura, T., Tsuda, T., and Kato, S.: Seasonal variability of vertical eddy diffusivity in the middle atmosphere: 1. Three-year observations by the middle and upper atmosphere radar, J. Geophys. Res., 99, 18973, https://doi.org/10.1029/94JD00911, 1994.

Garratt, J. R.: The inland boundary layer at low latitudes, Bound.-Lay. Meteorol., 32, 307-327, https://doi.org/10.1007/BF00121997, 1985.

Gentner, D. R., Ford, T. B., Guha, A., Boulanger, K., Brioude, J., Angevine, W. M., de Gouw, J. A., Warneke, C., Gilman, J. B., Ryerson, T. B., Peischl, J., Meinardi, S., Blake, D. R., Atlas, E., Lonneman, W. A., Kleindienst, T. E., Beaver, M. R., Clair, J. M. St., Wennberg, P. O., VandenBoer, T. C., Markovic, M. Z., Murphy, J. G., Harley, R. A., and Goldstein, A. H.: Emissions of organic carbon and methane from petroleum and dairy operations in California's San Joaquin Valley, Atmos. Chem. Phys., 14, 4955-4978, https://doi.org/10.5194/acp-14-4955-2014, 2014 a.

Gentner, D. R., Ormeño, E., Fares, S., Ford, T. B., Weber, R., Park, J.-H., Brioude, J., Angevine, W. M., Karlik, J. F., and Goldstein, A. H.: Emissions of terpenoids, benzenoids, and other biogenic gas-phase organic compounds from agricultural crops and their potential implications for air quality, Atmos. Chem. Phys., 14, 5393-5413, https://doi.org/10.5194/acp-14-5393-2014, 2014b.

Georgiadis, T., Rossi, F., and Nerozzi, F.: Inferring ozone deposition on agricultural surfaces: An application to herbaceous and tree canopies, Water Air Soil. Pollut., 84, 117-128, https://doi.org/10.1007/BF00479592, 1995.

Hegglin, M. I., Brunner, D., Peter, T., Staehelin, J., Wirth, V., Hoor, P., and Fischer, H.: Determination of eddy diffusivity in the lowermost stratosphere, Geophys. Res. Lett., 32, L13812, https://doi.org/10.1029/2005GL022495, 2005.

Hu, X.-M., Klein, P. M., Xue, M., Zhang, F., Doughty, D. C., Forkel, R., Joseph, E., and Fuentes, J. D.: Impact of the vertical mixing induced by low-level jets on boundary layer ozone concentration, Atmos. Environ., 70, 123-130, https://doi.org/10.1016/j.atmosenv.2012.12.046, 2013.

Kawa, S. R. and Pearson, R.: Ozone budgets from the dynamics and chemistry of marine stratocumulus experiment, J. Geophys. Res., 94, 9809, https://doi.org/10.1029/JD094iD07p09809, 1989.

Kleinman, L., Lee, Y.-N., Springston, S. R., Nunnermacker, L., Zhou, X., Brown, R., Hallock, K., Klotz, P., Leahy, D., Lee, J. H., and Newman, L.: Ozone formation at a rural site in the southeastern United States, J. Geophys. Res., 99, 3469, https://doi.org/10.1029/93JD02991, 1994.

Kondo, H., Murayama, S., Sawa, Y., Ishijima, K., Matsueda, H., Wada, A., Sugawara, H., and Onogi, S.: Vertical Diffusion Coefficient under Stable Conditions Estimated from Variations in the
Near-Surface Radon Concentration, J. Meteorol. Soc. JPN II, 92, 95-106, https://doi.org/10.2151/jmsj.2014-106, 2014.

Kraus, H., Malcher, J., and Schaller, E.: A nocturnal low level jet during PUKK, Bound.-Lay. Meteorol., 31, 187-195, https://doi.org/10.1007/BF00121177, 1985.

Lehning, M., Richner, H., Kok, G. L., and Neininger, B.: Vertical exchange and regional budgets of air pollutants over densely populated areas, Atmos. Environ., 32, 1353-1363, https://doi.org/10.1016/S1352-2310(97)00249-5, 1998.

Lenschow, D. H., Pearson, R., and Stankov, B. B.: Estimating the ozone budget in the boundary layer by use of aircraft measurements of ozone eddy flux and mean concentration, J. Geophys. Res., 86, 7291, https://doi.org/10.1029/JC086iC08p07291, 1981.

Lenschow, D. H., Li, X. S., Zhu, C. J., and Stankov, B. B.: The Stably Stratified Boundary Layer over the Great Plains, in: Topics in Micrometeorology, A Festschrift for Arch Dyer, 95-121, Springer, Dordrecht, 1988.

Li, J., Mahalov, A., and Hyde, P.: Impacts of agricultural irrigation on ozone concentrations in the Central Valley of California and in the contiguous United States based on WRF-Chem simulations, Agr. Forest Meteorol., 221, 34-49, https://doi.org/10.1016/j.agrformet.2016.02.004, 2016.

Lin, C.-H.: Impact of Downward-Mixing Ozone on Surface Ozone Accumulation in Southern Taiwan, J. Air Waste Manage. Assoc., 58, 562-579, https://doi.org/10.3155/1047-3289.58.4.562, 2008.

Lin, C.-H., Lai, C.-H., Wu, Y.-L., and Chen, M.-J.: Simple model for estimating dry deposition velocity of ozone and its destruction in a polluted nocturnal boundary layer, Atmos. Environ., 44, 4364-4371, https://doi.org/10.1016/j.atmosenv.2010.07.053, 2010.

Lin, Y.-L. and Jao, I.-C.: A Numerical Study of Flow Circulations in the Central Valley of California and Formation Mechanisms of the Fresno Eddy, Mon. Weather Rev., 123, 3227-3239, https://doi.org/10.1175/15200493(1995)123<3227:ANSOFC >2.0.CO;2, 1995.

Massman, W. J., Pederson, J., Delany, A., Grantz, D., den Hartog, G., Neumann, H. H., Oncley, S. P., Pearson, R., and Shaw, R. H.: An evaluation of the regional acid deposition model surface module for ozone uptake at three sites in the San Joaquin Valley of California, J. Geophys. Res., 99, 8281, https://doi.org/10.1029/93JD03267, 1994.

Mészáros, R., Horváth, L., Weidinger, T., Neftel, A., Nemitz, E., Dämmgen, U., Cellier, P., and Loubet, B.: Measurement and modelling ozone fluxes over a cut and fertilized grassland, Biogeosciences, 6, 1987-1999, https://doi.org/10.5194/bg-6-19872009, 2009.

Neirynck, J., Gielen, B., Janssens, I. A., and Ceulemans, R.: Insights into ozone deposition patterns from decade-long ozone flux measurements over a mixed temperate forest, J. Environ. Monit., 14, 1684-1695, https://doi.org/10.1039/C2EM10937A, 2012.

Neu, U.: A parameterization of the nocturnal ozone reduction in the residual layer by verticla downward mixing during summer smog situations using sodar data, Bound.-Lay. Meteorol., 73, 189-193, https://doi.org/10.1007/BF00708937, 1995.

Nieuwstadt, F. T. M.: The Turbulent Structure of the Stable, Nocturnal Boundary Layer, J. Atmos. Sci., 41, 2202-2216, https://doi.org/10.1175/15200469(1984)041<2202:TTSOTS>2.0.CO;2, 1984. 
Padro, J.: Summary of ozone dry deposition velocity measurements and model estimates over vineyard, cotton, grass and deciduous forest in summer, Atmos. Environ., 30, 2363-2369, https://doi.org/10.1016/1352-2310(95)00352-5, 1996.

Pederson, J. R., Massman, W. J., Mahrt, L., Delany, A., Oncley, S., Hartog, G. D., Neumann, H. H., Mickle, R. E., Shaw, R. H., Paw U, K. T., Grantz, D. A., MacPherson, J. I., Desjardins, R., Schuepp, P. H., Pearson, R., and Arcado, T. E.: California ozone deposition experiment: Methods, results, and opportunities, Atmos. Environ., 29, 3115-3132, https://doi.org/10.1016/13522310(95)00136-M, 1995.

Pilegaard, K., Hummelshøj, P., and Jensen, N. O.: Fluxes of ozone and nitrogen dioxide measured by Eddt correlation over a harvested wheat field, Atmos. Environ., 32, 1167-1177, https://doi.org/10.1016/S1352-2310(97)00194-5, 1998.

Pio, C. A., Feliciano, M. S., Vermeulen, A. T., and Sousa, E. C.: Seasonal variability of ozone dry deposition under southern European climate conditions, in Portugal, Atmos. Environ., 34, 195205, https://doi.org/10.1016/S1352-2310(99)00276-9, 2000.

Pisso, I. and Legras, B.: Turbulent vertical diffusivity in the sub-tropical stratosphere, Atmos. Chem. Phys., 8, 697-707, https://doi.org/10.5194/acp-8-697-2008, 2008.

Pun, B. K., Louis, J.-F., Pai, P., Seigneur, C., Altshuler, S., and Franco, G.: Ozone Formation in California's San Joaquin Valley: A Critical Assessment of Modeling and Data Needs, J. Air Waste Manag. Assoc., 50, 961-971, https://doi.org/10.1080/10473289.2000.10464140, 2000.

Rampanelli, G., Zardi, D., and Rotunno, R.: Mechanisms of Up-Valley Winds, J. Atmos. Sci., 61, 3097-3111, https://doi.org/10.1175/JAS-3354.1, 2004.

Salmond, J. A. and McKendry, I. G.: A review of turbulence in the very stable nocturnal boundary layer and its implications for air quality, Prog. Phys. Geogr.-Earth Environ., 29, 171-188, https://doi.org/10.1191/0309133305pp442ra, 2005.

Sander, S. P., Golden, D. M., Kurylo, M. J., Moortgat, G. K., Wine, P. H., Ravishankara, A. R., Kolb, C. E., Molina, M. J., Finlayson-Pitts, B. J., Huie, R. E., and Orkin, V. L.: Chemical kinetics and photochemical data for use in Atmospheric Studies Evaluation Number 15, Technical Report, Pasadena, CA, Jet Propulsion Laboratory, National Aeronautics and Space Administration, 2006, available at: https://trs.jpl.nasa.gov/handle/2014/ 41648 (last access: 6 August 2018), 2006.

Schmidli, J. and Rotunno, R.: Mechanisms of Along-Valley Winds and Heat Exchange over Mountainous Terrain, J. Atmos. Sci., 67, 3033-3047, https://doi.org/10.1175/2010JAS3473.1, 2010.

Smith, N., Plane, J. M. C., Nien, C.-F., and Solomon, P. A.: Nighttime radical chemistry in the San Joaquin Valley, Atmos. Environ., 29, 2887-2897, https://doi.org/10.1016/13522310(95)00032-T, 1995.

Steiner, A. L., Cohen, R. C., Harley, R. A., Tonse, S., Millet, D. B., Schade, G. W., and Goldstein, A. H.: VOC reactivity in central California: comparing an air quality model to ground-based measurements, Atmos. Chem. Phys., 8, 351-368, https://doi.org/10.5194/acp-8-351-2008, 2008.
Stewart, J. Q., Whiteman, C. D., Steenburgh, W. J., and Bian, X.: A climatological study of thermally driven wind systems of the u.s. intermountain west, B. Am. Meteorol. Soc., 83, 699-708, https://doi.org/10.1175/15200477(2002)083<0699:ACSOTD>2.3.CO;2, 2002.

Stull, R. B.: An Introduction to Boundary Layer Meteorology, Springer Netherlands, available at: https://www.springer.com/us/ book/9789027727688 (last access: 15 August 2018), 1988.

Stutz, J., Wong, K. W., Lawrence, L., Ziemba, L., Flynn, J. H., Rappenglück, B., and Lefer, B.: Nocturnal $\mathrm{NO}_{3}$ radical chemistry in Houston, TX, Atmos. Environ., 44, 4099-4106, https://doi.org/10.1016/j.atmosenv.2009.03.004, 2010.

Thorpe, S. A.: The Turbulent Ocean, Cambridge University Press, ISBN-13 978-0-521-83543-5 hardback, ISBN-10 0-521-83543-7 hardback, 2005.

Trousdell, J. F., Conley, S. A., Post, A., and Faloona, I. C.: Observing entrainment mixing, photochemical ozone production, and regional methane emissions by aircraft using a simple mixed-layer framework, Atmos. Chem. Phys., 16, 15433-15450, https://doi.org/10.5194/acp-16-15433-2016, 2016.

US Department of Commerce, N.: CalNex 2010 Data, available at: https://esrl.noaa.gov/csd/groups/csd7/measurements/ 2010calnex/ (last access: 7 August 2018), 2010.

Vilà-Guerau de Arellano, J., Patton, E. G., Karl, T., van den Dries, K., Barth, M. C., and Orlando, J. J.: The role of boundary layer dynamics on the diurnal evolution of isoprene and the hydroxyl radical over tropical forests, J. Geophys. Res., 116, D07304, https://doi.org/10.1029/2010JD014857, 2011.

Walton, S., Gallagher, M. W., Choularton, T. W., and Duyzer, J.: Ozone and $\mathrm{NO}_{2}$ exchange to fruit orchards, Atmos. Environ., 31, 2767-2776, https://doi.org/10.1016/S1352-2310(97)000964, 1997.

Wesely, M. L.: Parameterization of surface resistances to gaseous dry deposition in regional-scale numerical models, Atmos. Environ., 23, 1293-1304, https://doi.org/10.1016/00046981(89)90153-4, 1989.

Wilson, R.: Turbulent diffusivity in the free atmosphere inferred from MST radar measurements: a review, Ann. Geophys., 22 , 3869-3887, https://doi.org/10.5194/angeo-22-3869-2004, 2004.

Wood, E. C., Bertram, T. H., Wooldridge, P. J., and Cohen, R. C.: Measurements of $\mathrm{N}_{2} \mathrm{O}_{5}, \mathrm{NO}_{2}$, and $\mathrm{O}_{3}$ east of the San Francisco Bay, Atmos. Chem. Phys., 5, 483-491, https://doi.org/10.5194/acp-5-483-2005, 2005.

Zhang, J. and Rao, S. T.: The Role of Vertical Mixing in the Temporal Evolution of Ground-Level Ozone Concentrations, J. Appl. Meteor., 38, 1674-1691, https://doi.org/10.1175/15200450(1999)038<1674:TROVMI>2.0.CO;2, 1999.

Zhong, S., Whiteman, C. D., and Bian, X.: Diurnal Evolution of Three-Dimensional Wind and Temperature Structure in California's Central Valley, J. Appl. Meteor., 43, 1679-1699, https://doi.org/10.1175/JAM2154.1, 2004. 